\title{
Avaliação da resistência à fratura de dentes endodonticamente tratados, reconstruídos com pinos intra-radiculares, quando submetidos à ciclagem dinâmica.
}

\section{Fernando Furtado Antunes de Freitas}

Dissertação apresentada à Faculdade de Odontologia de Bauru, da Universidade de São Paulo, como parte dos requisitos para a obtenção do título de Mestre em Odontologia Área de Reabilitação Oral. 


\section{Avaliação da resistência à fratura de dentes endodonticamente tratados, reconstruídos com pinos intra-radiculares, quando submetidos à ciclagem dinâmica.}

\section{Fernando Furtado Antunes de Freitas}

Dissertação apresentada à Faculdade de Odontologia de Bauru, da Universidade de São Paulo, como parte dos requisitos para a obtenção do título de Mestre em Odontologia Área de Reabilitação Oral. 


\section{Freitas, Fernando Furtado Antunes de}

F884a Avaliação da resistência à fratura de dentes endodonticamente tratados, reconstruídos com pinos intra-radiculares, quando submetidos à ciclagem dinâmica. / Fernando Furtado Antunes de Freitas Bauru, 2007.

95 p.: il.; $30 \mathrm{~cm}$.

Dissertação (Mestrado) - Faculdade de Odontologia de Bauru. USP.

Orientador: Prof. Dr. Paulo Martins Ferreira.

Autorizo, exclusivamente para fins acadêmicos e científicos, a reprodução total ou parcial desta dissertação, por processos fotocopiadores e outros meios eletrônicos.

Bauru, de de 2007.

Assinatura:

Fernando Furtado Antunes de Freitas

Data de aprovação pelo Comitê de Ética da FOB/USP: 2802-2007

Número de protocolo: 77/2006. 



\section{Fernando Furtado Antunes de Freitas}

23 de fevereiro de 1978

Filiação

$1997-2001$

$2001-$

2002-2003

2003

2005-2007

Associações
Nascimento em Bauru - SP.

Deolinda Furtado de Freitas e César Antunes de Freitas.

Curso de Graduação em Odontologia na Universidade do Sagrado Coração (USC) Bauru.

Clínica particular, em Bauru.

Curso de Aperfeiçoamento em Odontologia Estética Contemporânea "Metal Free", na Associação Paulista de Cirurgiões-Dentistas APCD - Regional de Bauru.

Estágio no Departamento de Prótese da Faculdade de Odontologia de Bauru Universidade de São Paulo - Brasil.

Curso de Pós-Graduação em Odontologia, na área de Reabilitação Oral, da Faculdade de Odontologia de Bauru, da Universidade de São Paulo (FOB-USP), em nível de Mestrado.

APCD - Associação Paulista de CirurgiõesDentistas (APCD), Brasil.

SBPqO - Sociedade Brasileira de Pesquisa Odontológica. 
"O segredo de qualquer conquista é a coisa mais simples do mundo: saber o que fazer com ela"'.

(Panlo Coelho - O diário de nm Mago) 


\section{Dedicatória}

“É, também, no momento da escrita desta singela homenagem que me dou conta de que tudo em minha vida não tem sentido sem a presença de vocês".

Fernando F. A. de Freitas

Dedico esta obra aos meus Pais, Deolinda e César, exemplos de Sabedoria, Competência e Educação, cada um a seu modo. Na qualidade de educadores, me ensinam a buscar a excelência em todos os aspectos, sem nunca deixar a Ética de lado. Muito obrigado pela ajuda, apoio e confiança em todas as minhas conquistas. Os amo, em toda a plenitude do Amor. E como sou orgulhoso de ser uma parte de Vocês.

Ah... se no mundo houvesse mais de Vocês!

Aos meus Irmãos, Márcia e Vitor, Amigos confidentes. A cada momento aprendo, com Vocês, os prazeres da vida. Brigas 
intermináveis de dois minutos; carinhos e risadas de meia hora que se vão num segundo; olho no olho... sempre! Vocês são lindos! E sei que o são pela transparência das almas. Por tudo e por todos esses anos de alegria, muito obrigado. Amo Vocês!

À minha linda noiva, amiga, filha e mãe, Paola. Você me faz melhor, realiza meus sonhos. Sempre esteve ao meu lado, é meu apoio, me faz rir, flutuar. Brava, desde o primeiro momento! É um doce! Intensa, inteligente, romântica e carinhosa. Tua ausência nunca te levou pra longe de mim, mas sim pra perto, pra dentro deste coração. Sou teu... e só tenho a agradecer por Você fazer parte desta minha história. Muito obrigado por tudo! Te adoro y te amo.

Ao meu avô walter e à minha tia Marisa, companheiros de profissão, embora em diferentes épocas. Estou certo de que a Arte está no nosso sangue. Obrigado pela transmissão hereditária de seus ensinamentos, de alguma forma. 


\section{Agradecimentos especiais}

À toda Família Furtado, que sempre me apoiou e me incentivou. Aos tios Antônio, Carlos, Pina, Adilson, Silvio, Hermínia, Céu, Lídia, Meire, Lena e Chris. Aos primos Sérgio, Fábio, Adriana, Pérsio, Eliana, Bruna, Diego, Silvio, Carlos Alexandre, Juliana e Pedro.

À toda Família Antunes de Freitas, sempre na torcida, compartilhando cada momento. Aos tios Sérgio, Marisa, José Alberto, Cleide, Sinhana, Leta, Zezo, Daici, Marina e Geraldo. Aos primos Marina e José Henrique.

À minha Família Colán Guzmán, por toda a amizade, simpatia e carinho que tenho e que recebo de Vocês, Sr. Lúcio, Sra. Haydée e Karina. Muito obrigado por tudo o que sempre fizeram por mim, quando necessitei. 
Obrigado, também, pelo carinho de todos de Tacna e Huaral. Los quiero mucho!

Ao meu irmão, amigo e cunhado José Sergio, companheiro para todas as horas. Muito obrigado por sua amizade plena e verdadeira e, também, pela Família carinhosa e acolhedora que sempre me recebeu tão bem.

Aos meus irmãos, amigos e afilhados, Raquel e Aldrey, por todos os momentos vividos, desde muito tempo e que ainda são recordados, mesmo estando longe, o que torna nossa amizade cada vez mais plena. Muito obrigado pelo carinho das suas Famílias.

Aos grandes amigos Lili, Henrique e Miguel (Tutu) pela amizade, companheirismo e momentos agradáveis sempre que estamos juntos. Que nossa amizade envelheça como um bom vinho.

Ao grande amigo Breno, pela amizade recente, porém intensa. Por sempre estar 
presente e em prontidão para ajudar a qualquer momento. Já faz parte da Família.

Aos grandes amigos e cúmplices Gianina, Juan Carlos e Gonzalito. Sempre solícitos me dando apoio, conselhos, carinho e momentos inesquecíveis. E por me ajudar naquelas "mentiras brancas" sempre que precisei. Agradeço, de coração.

Aos amigos PC, Lucas, Érico, Kátia, Lívia, Luciana Rezende, Filipe e Cris, Rodrigo, Jeferson e Janaína, Paty, Leandro e Luciana, Fabiane e Rickson, Heraldo e Ana Paola, André e Cláudia, Alex e Rita, Dariel e Karen, Vinicius, Marcelo, Jarbas e Elisabeth, pelos bons momentos, confidências, gargalhadas, churrascos, festas, jogos de bola, ou aqueles simples momentos onde somente estarmos juntos faz valer a pena. Muito obrigado. 


\section{Agradecimentos}

À Faculdade de Odontologia de Bauru, da Universidade de São Paulo, representada pelo Prof. Dr. Luiz Fernando Pegoraro.

Ao Meu Orientador, Prof. Paulo Martins Ferreira, por me ensinar a arte se ensinar e pesquisar! Pelos conselhos amigos e pela saudável convivência. Pelo dom de transmitir toda sua Sabedoria com excelência. Muito obrigado!

Aos professores do Departamento de Prótese, Accácio Lins do Valle, Carlos dos Reis Pereira de Araújo, Gerson Bonfante, José Henrique Rubo, Lucimar Falavinha Vieira, Luiz Fernando Pegoraro, Milton Carlos Gonçalves Salvador, Paulo César Rodrigues Conti, Prof. Dr. Pedro César Garcia de Oliveira, Renato Freitas, Vinícius Carvalho Porto, Wellington Cardoso Bonachela, pelos ensinamentos, pela amizade 
e postura nos ensinando como ser um Professor.

Aos funcionários do Departamento de Prótese Cláudia, Reivanildo, Marcelo e Walquiria pela atenção e carinho em todos os momentos.

Ao Prof. Dr. César Antunes de Freitas, pelos conhecimentos e conselhos que levarei sempre em minha vida profissional e pessoal. São Professores como você que tornam o estudo mais prazeroso.

À Disciplina de Materiais Dentários, lugar onde foram realizadas algumas partes deste estudo. Pelo carinho de todos que lá trabalham e estudam. Um lugar onde sempre encontramos as "portas abertas" e somos bemvindos. Agradeço aos Profs. Paulo Afonso Silveira Francisconi, Paulo Amarante de Araújo e aos funcionários exemplares Sandra, Alcides e Lourisvalda. Muito obrigado pelo carinho e apoio. 
Ao Prof. Dr. José Mondelli, pela ajuda, convivência, pelos ensinamentos e pela amizade. Muito obrigado.

Ao Prof. Dr. José Roberto Pereira Lauris, pela orientação e confecção da análise estatística deste trabalho.

Aos funcionários do CIP-1, Prof. Dr. Vinícius de Carvalho Porto, Paulo Rosseti, Marcelo e dona Neusa, pela convivência fácil e agradável durante meus estudos. Muito Obrigado.

Aos Torneiros Mecânicos Renato e Ademir, Muito obrigado pela eficiência e precisão no trabalho realizado por vocês.

À minha Turma de Mestrado, Adriana Oshiro, Ana Paula Pedreira, Daniel Bayardo, Daniel Castro, Flora Freitas, Gabriela Vedolin, Jeferson Tomio, Luciana Rezende, 
Luis Eduardo, Rafael Moretti, Romão Mansano, Thiago Pegoraro e Valeria Lobato, pela convivência e pelo aprendizado, em todos os sentidos. Obrigado!

A todos os colegas de outras áreas, pela alegria de compartilharmos os bons e difíceis momentos do curso. Flaviane, Melaine, Karen, Milton, Erika, Carol, Dafna, Gianina, Rachele, Luis Felipe, Douglas, Ismar, Gustavo, Ian, Cristiane, Ronan, Marcio Taga, Mikaela, Cláudio, Thânia, Rafael Santos e Renato. Obrigado!

Aos novos mestrandos Davi, Marcelo, Paulo, Gustavo, Fabio, Daniel, osvaldo e Aline, por sempre ajudarem nas clínicas. Sucesso e muito obrigado.

Aos Amigos latinos, Gabriel, Gregory, Aldo, Fernando, Vladimir, Ramiro, Gina, Alba, Lina, Tati Lafuente e Esmeralda. Muchas gracias. 
Aos funcionários da Biblioteca pela solicitude e profissionalismo.

Aos funcionários da Pós Graduação da FOB, pela atenção e sempre disponibilidade, em particular à Giane, Letícia, Meg, Eduardo e Hebe.

Às empresas 3M ESPE, representada pela Mara, e Ângelus, pela disponibilidade, por atenderem prontamente meus pedidos e por me facilitar os seus produtos odontológicos para a confecção deste trabalho. Seu apoio foi fundamental para a concretização deste trabalho. Muito obrigado.

A todos os meus pacientes, pela convivência saudável, pela amizade cultivada durante o tempo e pela tolerância no período em que estive cursando o Mestrado. Muito obrigado.

A todos aqueles que me ajudaram, de alguma maneira, a concluir esta etapa da minha vida. Muito obrigado! 


\section{Sumário}

Resumo

xvii

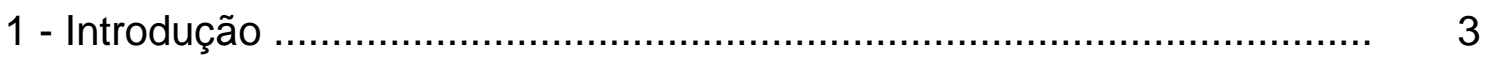

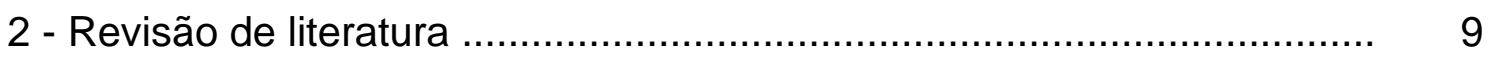

3 - Proposição …....................................................................... 21

4 - Materiais e métodos .................................................................. 25

5 - Resultados ............................................................................ 43

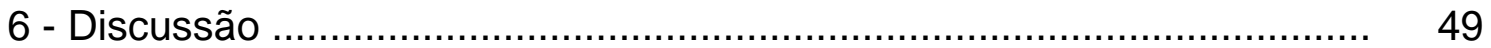

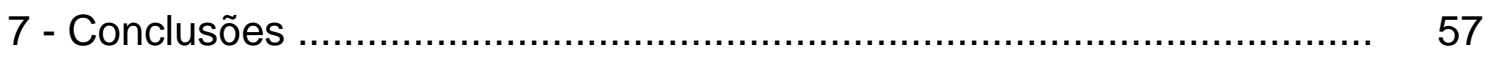

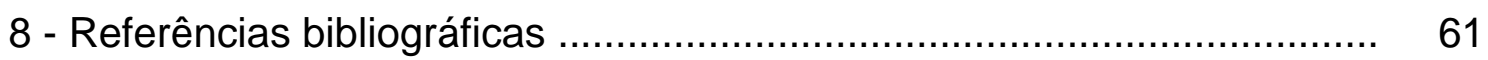

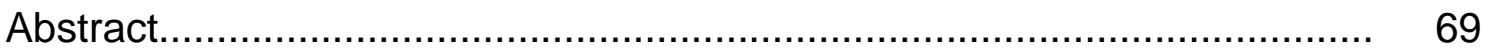

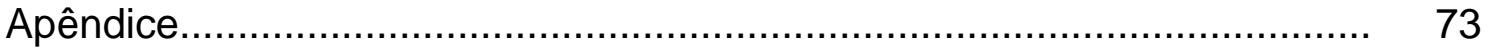




\section{Resumo}

Neste estudo, foi avaliada a resistência à fratura de dentes que, já tratados endodonticamente, foram reconstruídos proteticamente com uma coroa de liga de $\mathrm{NiCr}$ (Verabond II), a qual era apoiada sobre núcleos compostos por diferentes materiais, obtidos por diferentes técnicas, cimentados no remanescente radicular com o ionômero de vidro Rely $X$ Lutting 2, o qual é acrescido de resina composta. Esses núcleos eram do tipo metálico fundido, no grupo NMF; no grupo ANATO, a resina composta Filtek Z250 (3M ESPE, St. Paul-MN, USA) constituía o núcleo, contendo um pino de fibra de vidro (Reforpost Fibra de Vidro RX, Ângelus Indústria de Produtos Odontológicos Ltda.,Londrina-PR); este mesmo tipo de pino era utilizado no grupo PFFV, sendo diretamente cimentado, sem acréscimo de resina; finalmente, no grupo PFM, um pino metálico ( $n^{\circ}$ 064, FKG Dentaire S. A., La Chaux-de-Fonds, Swiss) era cimentado da mesma maneira descrita para o grupo anterior. Os remanescentes radiculares eram provenientes de dentes caninos superiores humanos, distribuídos aleatoriamente, compondo assim os quatro grupos, cada um com 10 espécimes: Os espécimes, após 24 horas da cimentação, foram submetidos a esforços cíclicos, em uma Máquina Eletro-Mecânica de Fadiga, aplicados no sentido do longo eixo dental, com carga de $20 \mathrm{~N}$, na freqüência de $2,0 \mathrm{~Hz}$, assim perfazendo um total de 250.000 ciclos. Excetuando-se 2 corposde-prova cujos núcleos soltaram-se da raiz, durante a carga cíclica, todos os demais foram submetidos a uma carga de compressão, numa máquina universal de ensaios (Kratos - Dinamômetros Ltda. São Paulo-SP), regulada na velocidade de $0,5 \mathrm{~mm} / \mathrm{min}$, com a força aplicada na face palatina da coroa, num ângulo de $45^{\circ}$ em relação ao longo eixo dental, até a ocorrência da fratura radicular. Os valores de resistência encontrados foram os seguintes, em ordem decrescente: 47,677 kgf para o grupo NMF, 34,921 kgf para o PFM, 31,354 kgf para o PFFV e, 27,172 kgf para o ANATO. A análise de variância aplicada aos valores originais apontou diferença entre os grupos estudados e um subseqüente teste de Tukey $(p<0,05)$ permitiu verificar semelhanças entre todos eles, com diferença significante apenas entre os grupos NMF e ANATO.

Palavras-chave: Raíz Dentária, Dente não-Vital, Pinos Dentários, Fadiga, Força Compressiva, Fratura dos Dentes. 

1 - Introdução 



\section{1 - Introdução}

Em Odontologia Restauradora, devem ser seguidos os princípios de manutenção e de restabelecimento da saúde bucal, para a promoção de uma condição saudável a um indivíduo. A manutenção deve ser realizada frente a um quadro de aparente normalidade, ocasião na qual o profissional deve efetuar tarefas simples e rotineiras, como profilaxia ou remoção de placa bacteriana. Qualquer tipo de tratamento somente deverá ser realizado quando existirem nítidas alterações da normalidade, ocasião na qual haverá a necessidade de serem efetuados procedimentos restauradores e/ou cirúrgicos, administração de drogas etc.

Intervenções restauradoras devem ser realizadas quando existirem, por exemplo: (a) lesões cariosas, as quais englobam desde alterações da cor ou da textura do esmalte, até a presença de cavidades nitidamente detectáveis; (b) fraturas do material restaurador, causadas pela perda de suporte dentinário, por erosão, por abfração ou ainda por enfraquecimento do remanescente coronário, em função da remoção desnecessária de estrutura sadia, durante a realização de procedimentos restauradores; ou (c) fraturas do remanescente dentário, causadas por algum dos motivos acima citados, por associação destes, ou ainda pelo enfraquecimento da estrutura dentária, em função de tratamento endodôntico ou de traumas, segundo BOTTINO et al. ${ }^{8}, 2001$.

Restaurar um elemento dentário significa devolver-Ihe a forma, a função e a estética, sendo de suma importância, para que se consiga alcançar os objetivos citados, o profundo conhecimento das técnicas envolvidas e dos materiais nelas empregados e no desenvolvimento destes.

MONDELLI et al. ${ }^{47}, 1980$, acreditavam que "dentes despolpados apresentam menor resistência à fratura, em relação a dentes vitais, principalmente pela perda de dentina removida durante o tratamento endodôntico, a qual confere elasticidade ao dente". Por esta razão, devem ser preservadas, ao máximo possível as estruturas dentárias, assim melhorando a sua capacidade de reter peças protéticas, assim como a de absorver e distribuir as forças da mastigação. 
Em muitas situações clínicas, há grande perda de estrutura coronária, com eventual envolvimento do tecido pulpar. A necessária recomposição do dente, caso a polpa esteja íntegra, pode ser alcançada através de procedimentos diretos, quando são, por exemplo, utilizados pinos rosqueáveis à dentina para a confecção de um núcleo de preenchimento. Caso o dente tenha sido endodonticamente tratado, sua restauração também pode ser realizada por meios indiretos, como quando são utilizados pinos fundidos em metal. Em quaisquer desses casos, devem ser adequadamente analisadas todas as características dos remanescentes radiculares e das estruturas adjacentes, para se alcançar um resultado final adequado, segundo BOTTINO $^{8}$, 2001, e PEGORARO ${ }^{52}, 1998$.

No ano de 1746 , FAUCHARD ${ }^{18}$ relatou empregar um pino de madeira, no interior do conduto radicular, para promover a retenção de uma coroa ao remanescente radicular. Os pinos de madeira foram muito utilizados no decorrer do século XIX, sendo que, em 1869, BLACK ${ }^{7}$ preferia utilizar a técnica que empregava o uso de um parafuso metálico para fixar coroas de porcelana ao conduto radicular, segundo MORGANO e BRACKETT ${ }^{49}, 1999$.

Muitos autores, que serão citados posteriormente, relataram que, a partir dessa data, houve uma grande evolução dos tipos de pinos utilizados nos tratamentos restauradores protéticos, passando-se a buscar não apenas uma adequada retenção das coroas, mas também um reforço da estrutura dentária remanescente.

Um determinado tipo de pino metálico foi rotineiramente utilizado, a partir do final do ano 1800 , sendo obtido através do processo de fundição e conhecido pelo nome "pivot". Este era composto por um pino intra-radicular e uma coroa, conformando uma única peça, segundo DEMAS $^{14}$, 1957, e HAMPSON e CLARK ${ }^{32}$, 1958. Por ser uma difícil técnica para sua confecção, aliada a uma eventual necessidade de sua remoção do interior do conduto, desenvolveu-se um pino intra-radicular, separado da porção coronária, o qual recebeu o nome de "núcleo metálico fundido", por apresentar íntima adaptação ao conduto radicular, uma alta resistência à fratura e fácil técnica de cimentação. Suas qualidades estão amplamente documentadas na bibliografia pertinente dos trabalhos de ASSIF e GORFIL ${ }^{02}, 1994$, HU et al. ${ }^{37}, 2003$, 
SORENSEN e ENGELMAN ${ }^{59}, 1990$, AL-HAZAIMEH e GUTTERIDGE¹, 2001, dentre outros.

No início da década de 1970, iniciou o uso de pinos metálicos préfabricados, cuja porção radicular era provida de roscas, para facilitar sua retenção ao remanescente radicular, na associação às resinas compostas e amálgama, para a confecção da porção coronária, como uma alternativa de tratamento, de acordo com SPALTEN ${ }^{61}, 1971$ e BARABAN ${ }^{4}, 1972$.

Pinos não-metálicos à base de compósitos reforçados com fibras associam um elemento de alta resistência (fibras de carbono, vidro, quartzo ou polietileno e cerâmico de zircônia) com matrizes resinosas, relatados nos trabalhos de FREEDMAN ${ }^{24}, 1996$ e FREILICH ${ }^{25}, 2000$.

LOWELL $^{41}$, na data de 1983, fez a primeira referência literária onde citou o uso de fibra de carbono para reforço. Mas isto era realizado artesanalmente e sem nenhuma comprovação científica.

DURET et al. ${ }^{15,16}$, em 1990, introduziam os pinos reforçados com fibra de carbono nas pesquisas de restauração de dentes que sofreram tratamento endodôntico.

VIRGIL e LAU ${ }^{65}, 1976$, LUI $^{42,43}, 1987$ e 1994, respectivamente, MENDOZA $^{46}, 1997$, afirmaram que a utilização destes pinos intra-radiculares aumenta a resistência à fratura do remanescente radicular, além de promover suporte à coroa.

GOLDBERG e BURSTONE ${ }^{26}$, em 1992, relataram que os pinos de fibras de vidro, especificamente, foram introduzidos no mercado, neste mesmo ano. Como estes foram recentemente desenvolvidos, há poucos estudos clínicos e/ou laboratoriais acerca de seu desempenho e longevidade, como relataram FERRARI et al. ${ }^{20}, 2000$, MONTICELLI et al. ${ }^{48} 2003$ e NAUMANN et al. ${ }^{50}, 2006$.

Para a utilização de pinos reforçados por fibras de vidro ou de carbono, tem se a necessidade de preencher o espaço restante do conduto radicular com resina.

GRANDINI e FERRARI ${ }^{29}$, em 2000, baseados nesses princípios, utilizaram uma raiz de dente, na qual não se encontrara nenhuma área que promovesse algum tipo de retenção mecânica no seu interior. O conduto radicular foi lubrificado com glicerina líquida, preenchido com resina composta 
e, posteriormente, introduzido um pino de fibra e a fotoativação realizada durante 20 segundos. O conjunto, então removido do interior do conduto, era fotoativado, novamente, durante 20 segundos. Com isso, conseguiu-se o denominado pino anatômico bem adaptado às paredes internas da raiz dental.

GRANDINI et al. ${ }^{30}$, em 2003, e GRANDINI ${ }^{31}$, em 2003, relataram que o pino anatômico deve ser utilizado rotineiramente nas clínicas e devem ser indicados para condutos alargados. Foi verificado, através de microscopia eletrônica de varredura que, pinos anatômicos apresentam espessura da película de cimento seis vezes menor do que as dos pinos pré-fabricados, havendo redução significativa do número e dimensão de bolhas na massa de cimento. A eficácia da técnica deve ser avaliada em estudos clínicos longitudinais, inexistentes até o momento.

STOCKTON $^{63}$, em 1999, em seu estudo, relatou que o aumento no comprimento do pino tem um efeito significante na sua retenção mecânica.

HUDIS e GOLDSTEIN ${ }^{38}$, em 1986, relataram que o aumento no comprimento do pino tem um efeito significante na sua resistência à fratura.

HOLMES et al. ${ }^{36}$, em 1996, afirma que o aumento no comprimento do pino tem um efeito significante causando a diminuição da concentração das tensões de cisalhamento.

BUTZ $^{11}$, em 2001, KOVARIK et al. ${ }^{40}$, em 1992 e PONTIUS e HUTTER ${ }^{54}$, em 2002, utilizaram uma carga cíclica afirmando que, desta forma, haveria uma simulação mais próxima da encontrada no ambiente oral do que a aplicação de uma carga progressiva, até que ocorra alguma falha, como é comumente realizado nos ensaios de resistência à fratura. Isto ocorre porque o padrão de carga cíclica muitas vezes é comparável à função fisiológica, podendo desta maneira, prever resultados de ensaios clínicos, ao longo do tempo. 
2 - Revisão de

literatura 


\section{2 - Revisão de literatura}

Devido à quantidade de trabalhos a respeito do assunto estudado, dividiremos este trabalho em tópicos, na intenção de facilitar o entendimento de cada uma das partes, porém, não respeitando uma ordem cronológica.

\section{Diagnóstico, indicação e seleção dos pinos para restauração.}

Segundo HEYDECKE e PETERS ${ }^{35}$, em 2002, BOUILLAGUET et al. ${ }^{9}$, em 2003 e NAUMANN; PREUSS; FRANKENBERGER ${ }^{50}$, em 2006, na Odontologia atual nos deparamos, rotineiramente, com situações onde um remanescente radicular sofreu um excessivo desgaste durante seu tratamento endodôntico. Para que se tenha êxito neste tipo de tratamento, deve ser indicada e realizada uma adequada restauração, onde se utilize um determinado tipo de pino intra-radicular. Porém, a maioria dos odontólogos, nesses casos, encontra dificuldades em eleger um, dentre tantos. Sabemos que a função de um pino intra-radicular constituído de qualquer um dos materiais é servir de suporte para a reconstrução da porção coronária do dente, e não reforçar a estrutura radicular remanescente.

BARABAN $^{5}$, em 1967, estudou a influência de determinados fatores na escolha de um método para a restauração de dentes que sofreram tratamento endodôntico. A quantidade de estrutura dentária coronal restante, a função que o dente exerce no arco dental e a oclusão (hábitos funcionais do indivíduo) seriam estes fatores. Quando indicado o uso de um pino intra-radicular, este deveria possuir um comprimento de, no mínimo, metade do comprimento da raiz. Se o dente tratado endodonticamente for submetido às forças oclusais excessivas (por exemplo, no bruxismo), este deve ser restaurado com pino, independentemente da quantidade da estrutura dentária remanescente.

STANDLEE; CAPUTO; HANSON ${ }^{62}$, em 1978, realizaram um estudo clínico onde estudaram quatro fatores importantes para a retenção do pino: o formato, o diâmetro e comprimento do pino, e o cimento. Segundo eles, duas seriam as funções dos pinos, sendo elas a de proteger o dente enfraquecido por razão do tratamento endodôntico e a de fornecer uma retenção adequada 
para a restauração da porção coronária. Os autores concluíram que os principais fatores de influência na retenção de um pino são o formato e comprimento do pino. O tipo de cimento e o diâmetro do pino parecem ter pouco efeito. Isto pode ser atribuído às variações na morfologia dos canais radiculares. O tipo de cimento pareceu importante apenas no uso de pinos cônicos.

SCOTTI e FERRARI ${ }^{58}$, em 2002, estudaram o efeito do tratamento endodôntico sobre os elementos dentários e concluíram que há o enfraquecimento dental em torno de $5 \%$ no geral, sendo que as alterações físico-mecânicas como a desidratação da dentina por razão da perda da irrigação sanguínea e a variação da disposição das fibrilas de colágeno aumentariam para 14 essa porcentagem.

FERNANDES; SHETTY; COUTINHO ${ }^{19}$, em 2003, realizaram uma revisão de literatura observando as variáveis que poderiam ser favoráveis ou não na indicação de um determinado tipo de pino na restauração de um remanescente radicular, quando existem diversos fatores determinantes para a sua seleção. Fatores relacionados ao indivíduo e sua estrutura dentária remanescente, anatomia dental (comprimento e largura da raiz) e do conduto, altura de estrutura coronária remanescente e força mastigatória. Entre os fatores relacionados à restauração propriamente dita, o desenho e material de constituição do pino (tanto na sua porção radicular quanto coronária), biocompatibilidade, possibilidade de remoção e/ou re-tratamento, capacidade de adesão ao cimento, material de reconstrução da porção coronária e material da coroa definitiva.

BATEMAN; RICKETTS; SAUNDERS ${ }^{6}$, em 2003, realizaram uma revisão sistemática sobre os diferentes tipos de pinos de fibra. Através do banco de dados MEDLINE, no período decorrente entre janeiro do ano de 1966 a julho de 2002. Encontraram 264 artigos relacionados ao assunto pertinente, dos quais 59 deles se adequavam aos critérios de inclusão que abrangiam artigos sobre pinos endodônticos pré-fabricados a base de fibras; apenas aqueles publicados em revistas de Odontologia; que apresentavam resumo em língua Inglesa. Os autores concluíram que, a maioria dos trabalhos relacionados envolve ensaios laboratoriais onde encontraram mais evidências científicas para os estudos de pinos de fibra de carbono em comparação aos 
de fibra de vidro; muitas das conclusões dos estudos são contraditórias; poucos estudos clínicos foram realizados embora sugiram que os pinos de fibra apropriados para o uso clínico em dentes que sofreram tratamento endodôntico.

GRANDINI $^{31}$, em 2003, relatou que seria possível realizar uma moldagem anatômica com resina composta fotopolimerizável que apresentasse pouca quantidade de carga, utilizando-se um pino pré-fabricado de fibra de quartzo obtendo-se, assim, um denominado "pino anatômico", o qual copiaria fielmente a forma interna de um conduto radicular. Com este estudo, pode-se concluir que a eficácia da descrita técnica deverá ser avaliada através de estudos clínicos e laboratoriais.

GRANDINI; SAPIO; SIMONETTI ${ }^{30}$, em 2003, relataram em seu trabalho que o "pino anatômico" deveria ser utilizado de maneira rotineira nas clínicas, indicado ao tratamento de remanescentes radiculares que apresentassem condutos alargados. A descrita técnica anularia uma fase laboratorial, como quando da confecção de um núcleo fundido em metal, sendo então realizada em somente uma fase clínica.

GOTO et al. ${ }^{28}$, em 2005, NAUMANN; PREUSS; FRANKENBERGER ${ }^{50}$, em 2006 e PEROZ et al. ${ }^{53}, 2005$ relataram que o uso de pinos em reconstruções de remanescentes radiculares não aumenta sua resistência à fratura, mas deve-se levar em consideração que a quantidade de estrutura remanescente coronária promove uma maior resistência à fratura ao conjunto. Mantendo-se a maior quantidade possível de estrutura e realizando-se técnicas de preparo mais conservadoras, podemos conseguir um possível efeito de férula, favorecendo o sucesso da restauração.

SALVI et al. ${ }^{57}$, em 2007, realizaram uma avaliação clínica para avaliar a taxa de sobrevivência ocorrida com 325 remanescentes radiculares, submetidos a tratamento endodôntico, sendo eles restaurados ou não com sistemas de pinos intra-radiculares, durante um período igual ou maior a 4 anos. Houve uma perda de 17 elementos dentários no decorrer desse estudo. Os elementos que receberam algum tipo de pino constituíam 80,5\% do total dos dentes examinados e, os restantes 19,5\%, não receberam pinos. A taxa de sobrevivência dos elementos foi, em média, de 6,2 anos para àqueles restaurados com pinos pré-fabricados em fibra de vidro e metal, 5,2 anos para 
os restaurados com pinos de titânio e, 4,4 anos para os que não receberam nenhum tipo de pino. Pode-se concluir, por meio desta avaliação que os elementos que receberam pinos intra-radiculares têm uma taxa de sobrevivência maior que àqueles que não receberam nenhum pino, em sua reconstrução.

\section{As prováveis causas de insucesso nas restaurações.}

MATTISON ${ }^{45}$, em 1982, estudou várias técnicas de restauração utilizando-se pinos. Alguns fatores predisponentes como quantidade de estrutura dentária remanescente, tipo de oclusão, suporte periodontal, espaço inter-oclusal, morfologia da raiz e do canal pulpar, foram analisados. O presente estudo demonstrou que, utilizando-se pinos com diâmetros de maior calibre e/ou de maior comprimento, somente seria possível realizando uma remoção excessiva de estrutura dentária remanescente. Isso causaria uma diminuição no volume dentário das paredes circundantes, na região apical do pino, onde ali se concentrariam tensões provenientes da mastigação. Portanto, estes procedimentos fragilizam a raiz, podendo ainda ocasionar uma perfuração desta.

BACHICHA et al. ${ }^{3}$, em 1998, SCOTTI e FERRARI ${ }^{58}$, em 2002, GOTO et al. ${ }^{28}$, em 2005, SAHAFI et al. ${ }^{56}$, em 2005 estudaram que, desde seu surgimento até meados dos anos 80 , o núcleo metálico fundido era considerado o melhor reforço, na reconstrução de dentes desvitalizados, quando cimentado com policarboxilato, fosfato de zinco ou ionômero de vidro. Porém, muitos estudos demonstram que, um elevado número de restaurações deste tipo fracassa com o passar do tempo, por razão das forças mastigatórias que são recebidas pela coroa são transmitidas à raiz, ocorrendo um efeito do tipo "cunha", no qual ocorre uma fratura radicular muitas vezes descrita como desfavorável, quando esta se propaga no sentido do longo eixo dental, em direção apical.

FERRARI e MANNOCCl ${ }^{22}$, em 2000, GORACCl et al. ${ }^{27}$, em 2005, CURY et al. ${ }^{13}$, em 2006, relataram que, uma das fases mais importantes para o sucesso de uma restauração, seria a cimentação adesiva realizada de forma 
passiva, absorvendo e distribuindo, assim, as tensões geradas a partir do atrito do pino a ser cimentado com as paredes do conduto.

FERRARI et al. ${ }^{20}$, em 2000, HEYDECKE e PETERS ${ }^{35}$, em 2002, ROBBINS ${ }^{55}$, em 2002, MONTICELLI et al. ${ }^{48}$, em 2003, TORBJORNER e FRANSSON ${ }^{64}$, em 2004, PEROZ et al. ${ }^{53}$, em 2005, HAYASHI et al. ${ }^{33}$, em 2006, analisaram as falhas clínicas que foram supostamente associadas aos dentes que sofreram tratamento endodôntico e restaurações que utilizaram pinos intraradiculares. Ao mesmo tempo, existem inúmeros materiais e métodos empregados e, muitas vezes, um critério para as falhas não está bem estabelecido, o que torna praticamente impossível justificar a indicação de um determinado sistema baseado apenas em estudos laboratoriais. Por essa razão, também é necessária a realização de estudos in vivo, mesmo sabendose que nesta situação, a variáveis encontradas no meio bucal são inúmeras.

FERNANDES; SHETTY; COUTINHO ${ }^{19}$, em 2003 estudaram a intensidade e a direção das forças oclusais, que são fatores muito importantes e não podem ser negligenciados, para que se consiga sucesso as restaurações.

TORBJORNER e FRANSSON ${ }^{64}$, em 2004, analisaram os principais sinais que poderiam levar o conjunto ao insucesso durante a restauração de um dente tratado endodonticamente, utilizando-se pinos. São eles: condutos radiculares excessivamente alargados, paredes circundantes delgadas e área de contato pequena, que resultaram em altos níveis de tensão sobre o cimento, sendo reportada como a mais freqüente causa de falhas, quando se há perda de retenção.

CHEN et al. ${ }^{12}$, em 2006, estudaram, através de uma análise de elemento finito, a correlação entre a quantidade desgastada de paredes circundantes de um remanescente radicular, sua resistência a fratura e a distribuição de tensões. As espessuras estudadas foram de 1,00 mm, 0,75 mm e $0,50 \mathrm{~mm}$ respectivamente quando comparadas com uma raiz que apresentava espessura normal de $1,2 \mathrm{~mm}$. Verificaram que com o aumento do diâmetro do conduto radicular, e quando estes eram submetidos a cargas, tanto verticais como laterais, eram geradas tensões nas paredes circundantes radiculares, diminuindo sua resistência á fratura. Eles concluíram que quando 
da necessidade de um tratamento endodôntico, deve-se remover apenas as porções de dentina infectada e eliminar áreas onde haja retenção mecânica.

Técnica e materiais utilizados para cimentação de pinos.

FERRARI et al. ${ }^{21}$, em 2000, estudaram o desempenho clínico de pinos de fibra cimentados, associados a 4 diferentes combinações sistema adesivo/cimento, durante períodos de 1 a 6 anos, realizando exames clínicos e radiográficos a cada seis meses. Eles observaram a soltura (ou de cimentação) dos pinos, por razão da necessidade de remoção da coroa provisória, e a presença de lesões periapicais, comprovadas através de exames radiográficos, porém não houve diferença estatisticamente significativa entre os grupos estudados, sendo considerada como aceitável a cimentação de pinos de fibra com resinas compostas.

SCOTTI e FERRARI ${ }^{58}$, em 2002, estudaram remanescentes radiculares reconstruídos utilizando-se pinos do tipo rígido (tendo como exemplo um pino fundido em metal ou um constituído por dióxido de zircônio), sendo estes fixados às raízes com um cimento resinoso. Os autores relataram que, quando o conjunto restaurado era submetido a forças oclusais maiores que o limite elástico do remanescente, haveria a perda de adesão entre o cimento resinoso e as paredes do conduto causando, assim, a soltura do pino garantindo a integridade do remanescente radicular.

HEYDECKE e PETERS ${ }^{35}$, em 2002, relataram que, o surgimento dos pinos intra-radiculares pré-fabricados em fibras de vidro, polietileno e dióxido de zircônio facilitou os procedimentos clínicos por possibilitar a restauração de um remanescente radicular em sessão única e, o surgimento dos pinos translúcidos permitiu a utilização de cimentos de polimerização dupla, pela razão da sua capacidade de transmissão da luz.

\section{Ensaios realizados e tipos de fratura encontrados.}

ESHELMAN e SAYEGH ${ }^{17}$, em 1983, estudaram a influência de diferentes tipos de pinos, constituídos de diferentes materiais, numa eventual fratura radicular. Os pinos utilizados eram constituídos de resina, aço inoxidável 
e ouro. Foram aplicadas cargas progressivas formando ângulos de 90 e $130^{\circ}$, em relação ao longo eixo dental. Relataram, neste estudo que, a carga aplicada em ângulo de $130^{\circ}$ simula uma situação mais natural, como 0 encontrado em pacientes portadores de oclusão do tipo classe I de Angle. Não foram encontradas diferenças significantes entre os diferentes tipos de material estudados, porém, houve diferença entre os ângulos de aplicação da carga. A carga no momento da fratura, nos ensaios em ângulo de $90^{\circ}$ foram de $52,8 \mathrm{~L}$ para os pinos de resina, 74,5L para os de aço e $64,9 \mathrm{~L}$ para os de ouro. Nos ensaios em $130^{\circ}$, as cargas eram de $11,1 \mathrm{~L}$ para os de resina, $116,8 \mathrm{~L}$ para os de aço e 104,1L para os de ouro. Relataram, também, que a área que apresentou menor resistência foi o terço apical da raiz, para as duas angulações estudadas, sendo que em $130^{\circ}$, a fratura estava localização na porção inferior do pino e, em $90^{\circ}$, estava localização numa área mais apical em relação à porção inferior do pino.

SORENSEN e ENGELMAN ${ }^{60}$, em 1990, estudaram a relação adaptação do pino/ resistência à fratura de dentes tratados endodonticamente, quando restaurados com pinos fundidos em metal e cimentados com fosfato de zinco. Uma íntima relação pino/conduto aumentou significantemente a resistência dos remanescentes ensaiados. Porém, essas fraturas não permitiam que esses remanescentes fossem restaurados. Pinos com formatos cônicos resultaram em linhas de fraturas direcionadas nos sentidos apicais e linguais. Pinos paralelos apresentavam linhas de fraturas envolvendo um menor volume de dentina.

MANNOCCl; FERRARI; WATSON ${ }^{44}$, em 1999, compararam o desempenho de dentes restaurados com pinos constituídos de fibra de quartzo, fibra de carbono-quartzo e de dióxido de zircônia, sendo que todos eram cobertos por coroas totais de cerâmicas, quando submetidos à aplicação de uma carga cíclica. Os pinos foram cimentados com "cimento resinoso" e a porção coronária confeccionada em resina composta recebendo então a coroa cerâmica. Após aplicação de uma carga cíclica de 250N a uma freqüência de 2 $\mathrm{Hz}$, formando ângulo de $45^{\circ}$ em relação ao longo eixo dental, foram observadas as falhas. Através da análise estatística, a taxa de sobrevivência dos pinos constituídos de dióxido de zircônia foi significantemente menor que 
as dos pinos de fibra, confirmando a necessidade de um pino quando toda a estrutura coronária do dente tratado endodonticamente estivesse perdida.

HEYDECKE et al. ${ }^{34}$, em 2002, estudaram a resistência à fratura de dentes quando restaurados utilizando-se pinos intra-radiculares de titânio, de zircônia e de zircônia. Pinos fundidos de ouro foram utilizados para o grupocontrole devido seu excelente desempenho, amplamente comprovado na literatura. Os pinos foram fixados com cimento resinoso e receberam com coroas totais. Foi aplicada uma carga cíclica de $30 \mathrm{~N}$, a uma freqüência de 2 $\mathrm{Hz}$, perfazendo um total de 1.200 .000 ciclos. Não houve diferença significante entre os grupos estudados e, com isso, os autores puderam concluir que os pinos de zircônia são tidos como uma adequada opção, quando comparados aos núcleos fundidos.

NEWMAN et al. ${ }^{51}$, em 2003, relataram em seu estudo que, quando ocorresse uma fratura e esta se localizasse abaixo do nível ósseo biológico, ou simulado quando em um estudo laboratorial, esta era caracterizada como desfavorável; e, quando localizada acima ou ao mesmo nível ósseo, seria caracterizada como favorável, mantendo-se então o remanescente dental para futuro reparo.

HU et al. ${ }^{37}$, em 2003, estudaram a resistência à fratura de dentes tratados endodonticamente, que apresentavam remanescente coronário com altura de $1 \mathrm{~mm}$, quando restaurados com quatro tipos de pinos, sendo eles núcleos metálicos fundidos, pré-fabricados paralelos e serrilhados, préfabricados em fibra de carbono e cerâmicos, recebendo, finalmente uma coroa total metálica. Os elementos foram submetidos à aplicação de carga compressiva, formando um ângulo de $45^{\circ}$ em relação a seu longo, até que ocorresse sua fratura. Os autores relataram não haver diferença estatisticamente significante entre os grupos sendo as piores fraturas àquelas observadas no grupo dos pinos cerâmicos. Fraturas desfavoráveis foram encontradas em todos os grupos havendo um maior número de fraturas radiculares, porém, conclui-se no presente estudo que, o fator mais importante para o aumento da resistência à fratura seria o uso de coroas totais e não a rigidez dos pinos intra-radiculares utilizados.

GOTO et al. ${ }^{28}, 2005$, estudaram a influência da ciclagem dinâmica, variando o número de ciclos utilizados, até que ocorresse algum tipo de falha 
na união entre a restauração e o remanescente radicular. Através deste estudo, relataram que as restaurações realizadas utilizando-se pinos de fibra de vidro cimentados com resina composta, sendo a porção coronária também reconstruída com resina apresentaram maior resistência em relação àquelas reconstruídas com núcleo fundido em ouro e pré-fabricados em liga de titânio.

JUNG et al. $^{39}$, em 2007, compararam a infiltração e a classificação dos padrões de fratura de dentes submetidos a tratamento endodôntico, restaurados com diferentes sistemas de pinos intra-radiculares, quando submetidos a uma carga dinâmica de 98 N, a uma freqüência de $1 \mathrm{~Hz}$, durante 50.000 ciclos, em ângulo de $135^{\circ}$, estando imersos em solução de fucsina básica a 0,5\%. Foram utilizados pinos pré-fabricados em resina reforçados por fibra de vidro Postec (que já eram cimentados aos remanescentes diretamente utilizando a resina composta fotopolimerizável Light-Core), em metal (ParaPost), e cerâmicos (Cosmopost), sendo estes últimos, cimentados com a resina composta de polimerização dupla DuoLink. Os autores concluíram que o grupo que recebeu pinos reforçados por fibra de vidro apresentou maiores níveis significantes de infiltração, quando comparados aos outros grupos. Ambos os grupos Postec e Cosmopost apresentaram menores índices de infiltração, quando submetidos à carga dinâmica e padrões de fraturas que favoreciam sua restauração.

Assim, todavia restam dúvidas a respeito da indicação de um determinado tipo de pino para a restauração de um remanescente radicular ou um sistema adesivo adequado e cimento ideal para este conjunto. Por essas razões, é importante que se conheça como ocorreu a evolução desses materiais e, principalmente, quais as características que os consolidaram como alternativa viável e aceitável à sua indicação. 

3 - Proposição 



\section{3 - Proposição}

Diante da necessidade de desenvolverem-se técnicas capazes de restaurar, de forma adequada, raízes que apresentam condutos medianamente alargados, bem como da investigação das propriedades mecânicas destas raízes quando reconstruídas com diferentes tipos de pinos (fundido em metal, pré-fabricado em fibra de vidro, pino anatômico e pré-fabricado metálico), o presente estudo teve como objetivos:

1. Avaliar a resistência à fratura de dentes tratados endodonticamente com condutos medianamente alargados, reconstruídos com diferentes sistemas de núcleos;

2. Avaliar o padrão de fratura ocorrido nestes dentes, quando submetidos à carga compressiva oblíqua ( $135^{\circ} \mathrm{com}$ o longo eixo da raiz). 
4 - Materiais

e métodos 



\section{4 - Materiais e métodos}

\subsection{Coleta e limpeza dos dentes.}

No presente estudo, foram utilizados 40 dentes humanos (caninos superiores), com dimensões muito similares entre si, doados pelo Posto de Saúde da cidade de Agudos - SP, os quais não apresentavam qualquer tipo de restauração, lesão cervical (cárie, erosão, abrasão ou abfração), defeitos radiculares ou tratamento endodôntico prévio. Com os dentes selecionados, foram compostos 4 grupos de 10 elementos; cada grupo foi armazenado num recipiente plástico, imerso em solução antifúngica isotônica de cloreto de sódio com $0,1 \%$ de timol. Os elementos dentários foram lavados, esterilizados em autoclave (a $121^{\circ} \mathrm{C}$, por 15 minutos, sob efeito de 1,5 atm de pressão) e recolocados na solução antifúngica. Cada elemento foi então raspado (com o auxílio de uma cureta periodontal), polido (com pasta utilizada para profilaxia, aplicada com uma escova de cerdas tipo Robinson) e recolocado na solução.

Para que os dentes escolhidos tivessem dimensões tão semelhantes quanto possível, a estratégia foi confeccionar, nas suas raízes, marcas nas alturas de 5, 10 e 15 mm, a partir do ápice, em direção coronária, nas quatro faces externas de cada dente. Cada raiz apresentava, em média, o comprimento de $17 \mathrm{~mm}$; no sentido mesio-distal, sua espessura era de 3,2 $\mathrm{mm}, 4,2 \mathrm{~mm}$ e $5 \mathrm{~mm}$, respectivamente, nas alturas referidas; no sentido vestíbulo-palatino, estas dimensões eram $5 \mathrm{~mm}, 6,8 \mathrm{~mm}$ e 7,5 mm. Todas estas mensurações foram efetuadas com o auxílio de um paquímetro digital Modelo 727-6/150 (Starrett Indústria e Comércio Ltda., Itu - SP).

\subsection{Molde para as futuras coroas metálicas.}

A porção coronária de um dos dentes coletados foi moldada com a silicona Optosil Confort (Heraeus Kulzer, do Brasil), apresentada na forma de massa. A porção coronária do referido dente foi verticalmente introduzida no interior da massa de silicona colocada em um pote de vidro tipo Dappen, como mostra a figura 1a; após 10 minutos de polimerização da silicona, o dente era dela removido e o molde apresentava-se como mostra a figura 1b. Neste, foram confeccionados, com a menor espessura possível, 40 casquetes em 
resina acrílica DuraLay (Reliance Dental Mfg. Co. Worth - Illinois, USA), utilizando a tradicional técnica do pincel; um destes está apresentado na figura 1c.

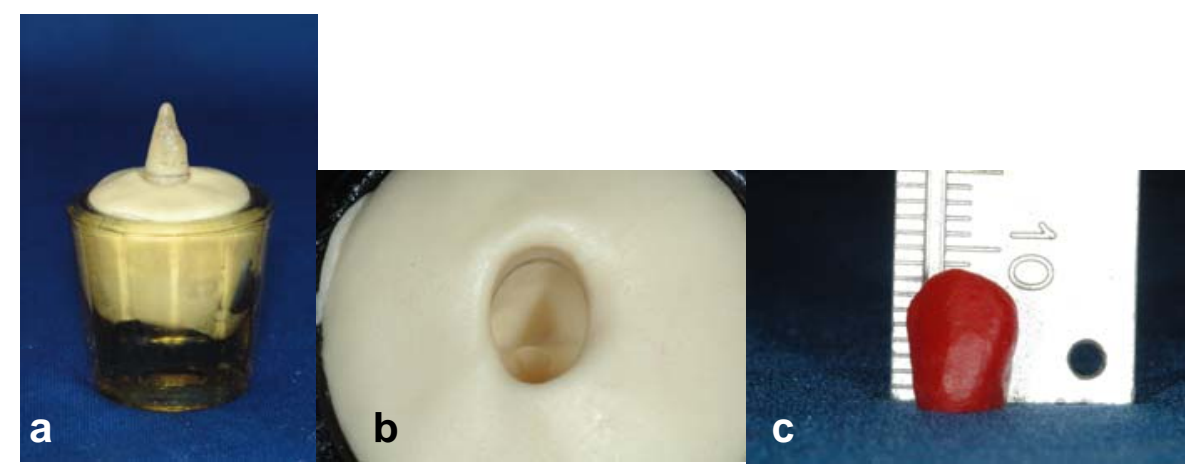

Figura 1 - Coroa dental sendo moldada (a); o respectivo molde (b) e um casquete de resina (c).

Em seguida, cada elemento dentário sofreu tratamento endodôntico e teve sua coroa eliminada, como será detalhadamente descrito a seguir.

\subsection{Tratamento endodôntico.}

A abertura da câmara coronária, para terapia endodôntica, foi executada da forma convencional. Para a instrumentação, utilizaram-se limas de aço inoxidável comuns, sob abundante irrigação efetuada com líquido de Dakin, uma solução de hipoclorito de sódio a 0,5\% (Biodinâmica Química e Farmacêutica Ltda., Ibiporã - PR), sendo a secagem dos condutos realizada com cones de papel absorvente comuns.

Os condutos foram preparados, de modo que seu limite ficasse $1 \mathrm{~mm}$ aquém do ápice radicular; para tanto, foram utilizadas limas comuns dos diferentes calibres existentes, até a de $n^{\circ} 60$, da $1^{a}$ série, como estabelecido pela International Standartization Organization (ISO); a obturação foi efetuada com cones de guta-percha de $\mathrm{n}^{0} 60$; o cimento utilizado foi o Sealer 26 (Dentsply Industria e Comércio Ltda., Petrópolis - RJ).

\subsection{Eliminação da porção coronária.}

Cada dente foi seccionado com disco adiamantado de dupla face, sob refrigeração por aerossol de ar/água, na junção cemento-esmalte, de forma perpendicular ao seu longo eixo. Este corte foi realizado numa altura acima da marca de $15 \mathrm{~mm}$, para permitir o posterior rebaixamento da superfície oclusal 
do remanescente radicular e seu subseqüente aplainamento, após sua fixação num cilindro de resina, como será explicado a seguir.

\subsection{Fixação das raízes em cilindros de resina.}

Usando um molde de silicona, cuja cavidade cilíndrica apresentava 20 $\mathrm{mm}$ de diâmetro interno e profundidade de $25 \mathrm{~mm}$, foram confeccionados 40 cilindros em resina acrílica auto-polimerizável incolor (Clássico Artigos Odontológicos S.A., Campo Limpo Paulista - SP). Após sua polimerização, cada cilindro era adaptado a um torno mecânico comum, no qual seus extremos foram aplainados (de modo que ficassem paralelos entre si), passando a altura para $20 \mathrm{~mm}$, mas mantendo-se o diâmetro original. A seguir, também no torno, confeccionou-se no cilindro um orifício central com $10 \mathrm{~mm}$ de diâmetro e 15 mm de profundidade, onde seria fixada uma raiz; nesta, para possibilitar a padronização de uma determinada distância, uma nova marca foi feita na altura de $12 \mathrm{~mm}$, partindo de seu ápice.

Uma broca de Largo $n^{0} 1$ (Dentsply Maillefer, Ballaigues, Switzerland) foi então aquecida e introduzida na guta-percha do conduto obturado, com o cuidado de mantê-la alinhada com o longo eixo da raiz. Após o esfriamento, a broca presa à raiz foi fixada à haste vertical de um Delineador B2 (Bio-Art Equipamentos Odontológicos, São Carlos - SP). Esta haste era então abaixada, para posicio nar a raiz no interior do cilindro, em posição central e perpendicularmente à sua base, até que a marca estivesse na mesma altura da face superior do cilindro. A haste era então levantada e o orifício do cilindro era preenchido (até 2/3 de sua altura) por resina acrílica, em sua fase arenosa. Abaixou-se novamente a haste, até que a raiz ficasse imersa na resina em seus $12 \mathrm{~mm}$ apicais, como está ilustrado pela figura 2.

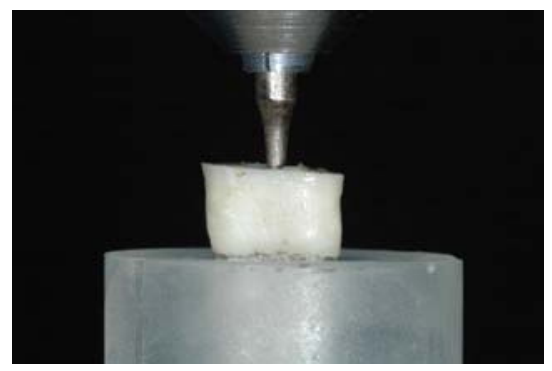

Figura 2 - Raiz centralizada no cilindro, com a marca de $12 \mathrm{~mm}$ na mesma altura da face superior do cilindro. 
Após 10 minutos de polimerização, o conjunto broca / raiz era removido do delineador e a broca era dele removida; cada um dos 4 conjuntos compostos por 10 raízes era numerado de 1 a 10, com uma caneta de tinta indelével.

O aplainamento da face oclusal de cada raiz era promovido através de um conjunto micromotor / peça reta, o qual era acoplado à haste do delineador, com o auxílio de uma peça denominada Suporte para micromotor (Bio-Art Equipamentos Odontológicos, São Carlos - SP); na peça reta era fixado um mandril com um disco adiamantado Dupla Face $n^{0} 7020$ (KG Sorensen do Brasil, São Paulo - SP). Um cilindro acrílico era então colocado na base do delineador, como ilustrado pela figura $3 \mathrm{a}$, onde era manualmente imobilizado pelo operador. Com o motor acionado, o disco era encostado na superfície oclusal da raiz, desgastando-a, como está ilustrado na figura $3 b$, até que restassem $3 \mathrm{~mm}$, verticalmente contados a partir da face superior do cilindro, medidos com o auxílio de uma régua milimetrada, ilustrado pela figura $3 \mathrm{c}$. Com isso, a referida superfície ficava perpendicularmente posicionada, em relação ao longo eixo do conduto radicular.

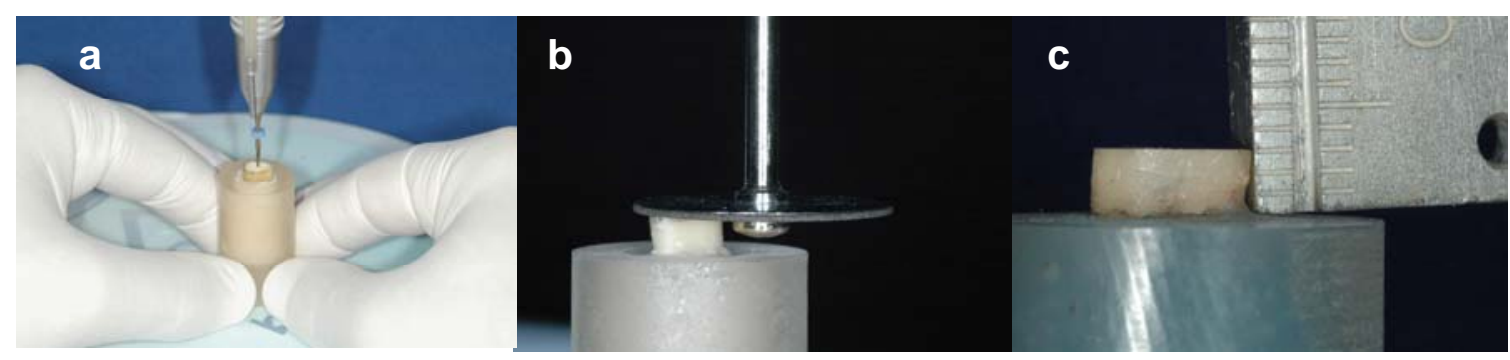

Figura 3 - Um cilindro fixo pelas mãos do operador (a); o aplainamento da face oclusal (b) e a medição da altura do remanescente radicular (c).

\subsection{Preparo dos condutos radiculares.}

O material obturador de cada raiz foi parcialmente removido com pontas Rhein aquecidas; a seguir, foi utilizada uma broca de Largo de $n^{\circ} 3$, adaptada numa peça reta que, girando em baixa-rotação, promoveu um desgaste até a profundidade de $10 \mathrm{~mm}$, servindo de guia de penetração. Em seguida, executou-se um desgaste semelhante, agora com uma broca de Largo $n^{0} 6$, a qual possuía 1,8 mm de diâmetro; a aparência do conduto, nesta ocasião, está ilustrada pela figura 4a. A seguir, era usada uma ponta adiamantada 3017HL (KG Sorensen do Brasil, São Paulo - SP), com 2,5 mm de diâmetro na sua parte ativa, penetrando $5 \mathrm{~mm}$ no interior do conduto, em condições 
semelhantes às já descritas; a aparência do conduto, nesta ocasião, está ilustrada pela figura $4 b$.

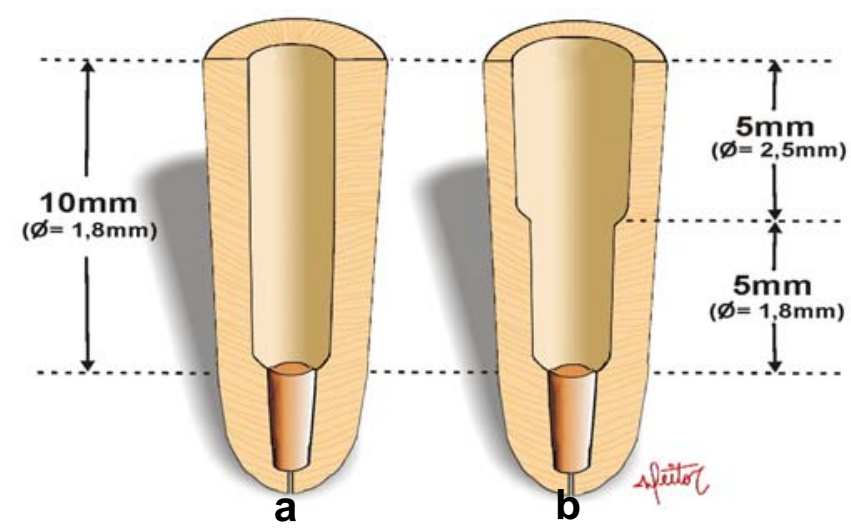

Figura 4 - Representação dos preparos intra-radiculares: primeiro desgaste (a) e segundo (b).

Uma vista oclusal do conduto de uma das raízes assim preparadas está ilustrada pela figura 5 .

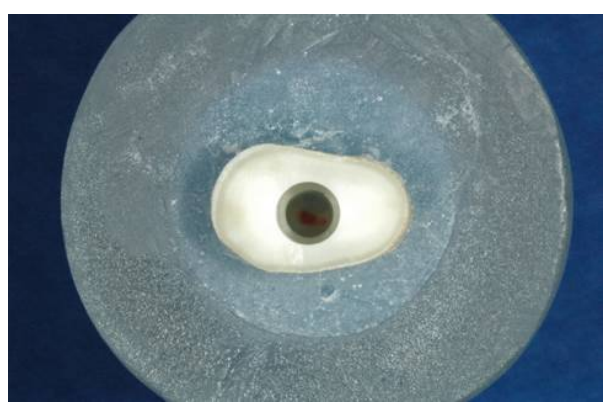

Figura 5 - Vista incisal após o preparo, onde se podem observar seus diferentes diâmetros.

Uma sonda periodontal milimetrada foi utilizada para controlar a profundidade de penetração das referidas pontas, juntamente com limitadores de borracha. Assim, considerava-se a raiz pronta para receber um núcleo; todos os futuros espécimes teriam seus núcleos cimentados com Rely $X$ Luting 2 (3M ESPE, St. Paul - MN, USA), um ionômero de vidro modificado por resina, assim compondo os quatro grupos experimentais esquematizados na figura $6 \mathrm{e}$ caracterizados a seguir, de forma sintética. 


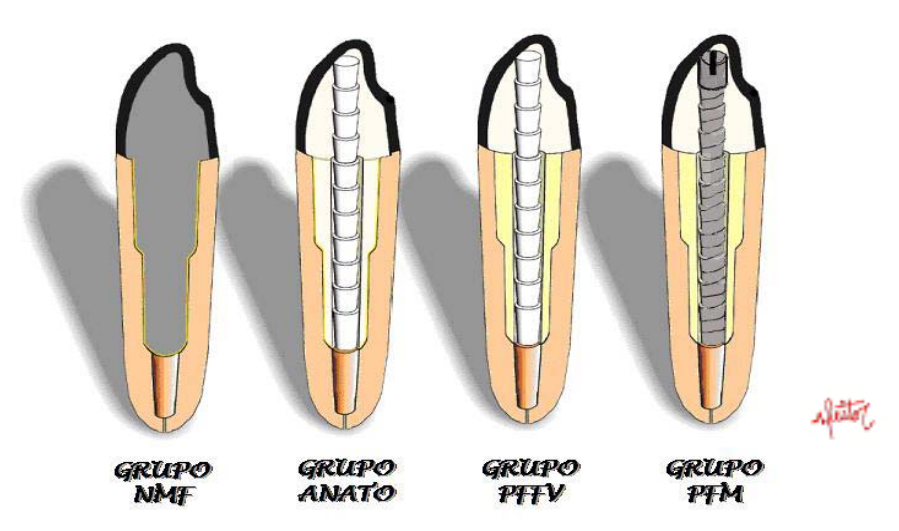

Figura 6 - Representação esquemática dos quatro grupos experimentais. [Desenho modificado do original de Kaiser, 2003.]

No primeiro grupo, denominado NMF, o núcleo seria do tipo metálico fundido. No segundo, denominado ANATO, este seria constituído por um pino de resina epóxica (reforçado por fibra de vidro) acrescido de resina composta, referido na literatura como "anatômico". No terceiro, denominado PFFV, este seria constituído pelo mesmo pino utilizado no segundo grupo, porém sem o acréscimo de resina composta. No quarto, denominado PFM, este seria constituído por um pino de metal inoxidável. Em todos estes grupos, o núcleo ainda apresentaria uma porção coronária de forma e dimensões semelhantes; adicionalmente, a espessura da película de cimento seria menor nos dois primeiros grupos e maior nos demais; a porção coronária dos núcleos nos três últimos grupos seria basicamente constituída por resina composta; todos esses aspectos serão detalhadamente descritos mais à frente, pois é necessário que antes seja explicado como foi confeccionado um núcleo-padrão, para que existisse uma padronização da porção coronária dos demais núcleos do presente estudo.

\subsection{Confecção do núcleo-padrão.}

No conduto de uma raiz tomada ao acaso, foi aplicado o lubrificante hidrossolúvel K-Y Gel (Johnson e Johnson Comércio e Distribuição Ltda, São Paulo - SP), com o auxílio de uma ponta aplicadora (Microbrush Corporation, Grafton - WI, USA), aguardando-se 2 minutos para seu secamento. Utilizandose a tradicional técnica do pincel, o conduto foi preenchido por resina acrílica auto-polimerizável DuraLay, na qual introduziu-se um pino (também de resina 
acrílica) do conjunto Pin-Jet (Ângelus - Indústria de Produtos Odontológicos Ltda - Londrina - PR). Após 10 minutos, com o auxílio de uma pinça hemostática, removeu-se o pino do conduto e seus excessos foram eliminados, com o auxílio de uma broca de carbeto de tungstênio Maxicutt (Edenta/Labordental, São Paulo - SP). Após aferição visual do pino, uma régua milimetrada foi usada para conferir o comprimento de sua porção radicular, nos seus dois segmentos, de diferentes diâmetros. Após tal confirmação, este foi recolocado no conduto. Uma matriz coronária do conjunto Pin-Jet, também constituída por resina acrílica vermelha, foi preenchida com DuraLay e levada sobre o pino, com suas faces vestibulares (da matriz e da raiz) voltadas para o mesmo lado. Após 10 minutos, esse núcleo de resina era retirado do conduto; após a eliminação de seus excessos, ele ficava com a aparência ilustrada pela figura $7 \mathrm{a}$ e era considerado pronto para ser o modelopadrão no subseqüente procedimento de fundição. Neste processo, utilizando a técnica da cera perdida, utilizou-se a liga de $\mathrm{NiCr}$ Verabond 2 (AalbaDent Inc., Califórnia, USA), seguindo-se as recomendações do fabricante. Assim foi obtido o núcleo-padrão ilustrado pela figura $7 \mathrm{~b}$.

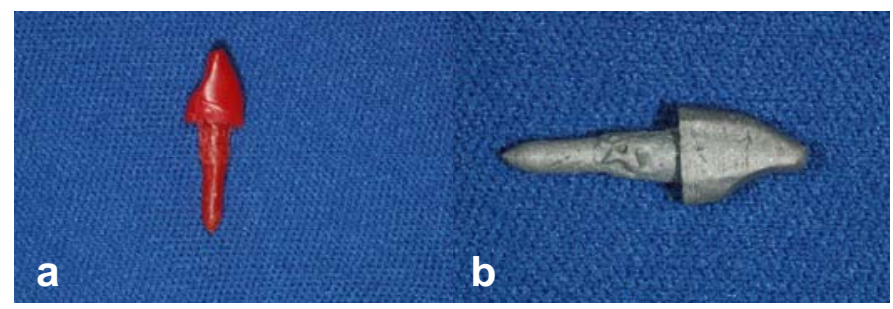

Figura 7 - Modelo-padrão (a) e núcleo-padrão (b).

Usando-se uma lupa (Bio-Art Equipamentos Odontológicos. Ltda São Carlos - SP), com aumento linear de 4 vezes, nódulos existentes no núcleopadrão foram eliminados com auxílio de uma broca esférica, de carboneto de tungstênio, girando em alta-rotação. Em seguida, uma fina camada de solução evidenciadora de contatos Arti-Spot 2 (Bausch Articulating Papers Inc., Nashua - NH, USA) era aplicada na sua porção radicular, para permitir uma adequada adaptação à raiz. A seguir, com o objetivo de padronizar suas dimensões coronárias, foram usadas pontas adiamantadas para desgastá-lo, reduzindo sua altura para $5,5 \mathrm{~mm}$ e suas espessuras para $4,5 \mathrm{~mm}$, no sentido vestíbulolingual, e 3,0 mm, no mesio-distal, ficando com a aparência e respectivas 
dimensões ilustradas na figura 8. Ele era então usado para auxiliar a confecção de uma matriz que permitisse a padronização das dimensões da porção coronária dos núcleos futuramente construídos.

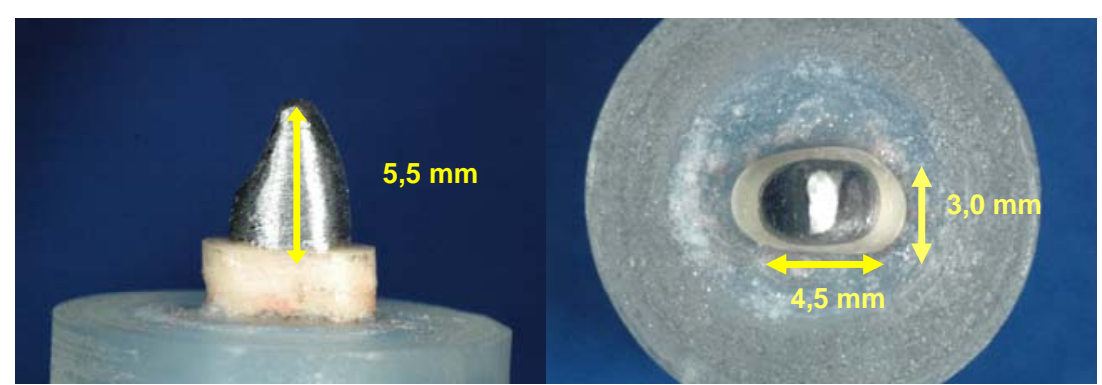

Figura 8 - Ilustração da porção coronária de um núcleo e suas respectivas dimensões.

\subsection{Confecção da matriz coronária incolor.}

O núcleo-padrão foi então acoplado a uma raiz e, sobre sua porção coronária, foi confeccionada uma peça denominada matriz coronária, constituída pela resina acrílica incolor já referida. Ela apresentava uma face inferior plana e, na sua vertente inferior foram feitas 4 marcas, referentes às faces vestibular, lingual e cada uma das proximais, como ilustra a figura 9a. Estas marcas serviriam de referência para o alinhamento da matriz sobre as raízes, nas quais também foram feitas marcas semelhantes. Este era efetuado nos sentidos mesio-distal e vestíbulo-lingual, como ilustrado pelas figuras $9 \mathrm{~b}$ e $9 \mathrm{c}$, respectivamente, nas quais a letra $\mathrm{V}$ indica a face vestibular.



Figura 9 - Matriz coronária: vista por sua face inferior (a), por vestibular (b) e por proximal (c).

\subsection{Confecção dos núcleos do grupo NMF.}

O núcleo-padrão foi aproveitado como sendo o primeiro dos núcleos deste grupo, pareado com a raiz usada em sua confecção. Para a confecção dos 9 núcleos restantes, foram seguidos basicamente os mesmos passos, porém, ao invés da matriz coronária do conjunto Pin-Jet, foi agora utilizada a matriz coronária incolor, para a construção da porção coronária, obtendo, assim, os modelos-padrão restantes. Os subseqüentes procedimentos de 
fundição e de adaptação foram realizados da maneira já descrita. Todas as dimensões dos 9 núcleos assim obtidos eram conferidas com as do núcleopadrão, compondo com aquele os 10 elementos constituintes do grupo, estando prontos para a cimentação.

\subsection{Confecção dos núcleos do grupo ANATO.}

Neste grupo, foi utilizado o pino Reforpost Fibra de Vidro RX $n^{0} 03$, (Ângelus Indústria de Produtos Odontológicos Ltda, Londrina - PR), constituído por fibra de vidro imersa em uma matriz de resina epóxica; cujas dimensões constam no esquema da figura 10a. Um desses pinos era introduzido no conduto radicular de uma das raízes (tomada ao acaso), até tocar a porção apical do conduto. Sua extensão extra-radicular de $10 \mathrm{~mm}$ era diminuída para 5,5 mm, através de corte efetuado com um disco adiamantado, sob irrigação abundante com aerossol ar-água. Sua centralização no conduto era visualmente verificada e sua altura confirmada com uma régua milimetrada, como mostrado pelas figuras 10b e 10c, respectivamente.

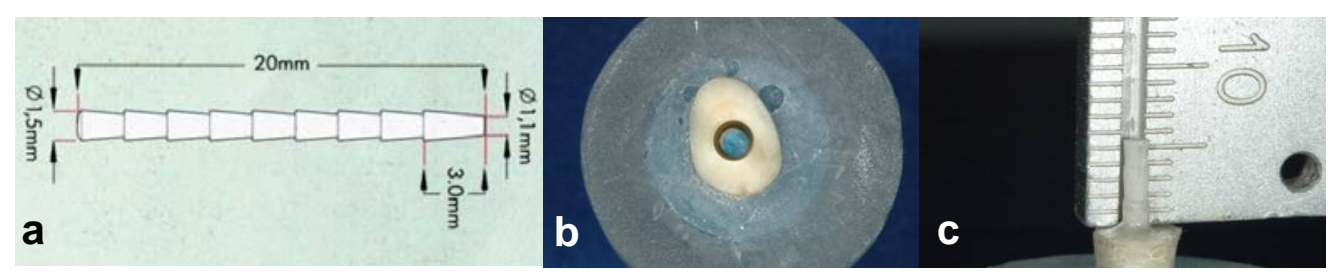

Figura 10 - Dimensões do pino Reforpost (a); sua centralização no conduto (b) e altura final (c).

O pino era desengordurado, durante 1 minuto, pela friç̧ão de uma gaze embebida com álcool etílico, sendo manipulado, a partir de então, com o auxílio de uma pinça hemostática comum. Uma camada do agente Silano (Ângelus Indústria de Produtos Odontológicos Ltda, Londrina - PR), era nele aplicada com auxílio de uma nova ponta e, conforme indicação do fabricante, secada após um minuto com suaves jatos de ar, a uma distância de 5 a $6 \mathrm{~cm}$. A seguir, eram aplicados os componentes do sistema adesivo Scotchbond Multi-Uso Plus (Dentsply Ind e Com. Petrópolis - RJ), que apresenta dupla polimerização. Inicialmente, foi aplicado o ativador nos interior dos condutos, com o auxílio de uma ponta aplicadora própria, seguido da secagem, efetuada com suaves jatos de ar, a uma distância de 5 a $6 \mathrm{~cm}$. Em seguida aplicou-se o primer, seguido 
pelo catalisador do citado sistema, sendo a fotoativação realizada durante 50 segundos, através de um aparelho XL1500 (3M ESPE, St. Paul - MN, USA).

Sobre o pino era então acomodada uma porção de resina composta Filtek Z-250 (3M ESPE, St. Paul - MN, USA), com o auxílio de uma espátula de inserção comum, de modo que a resina cobrisse a extensão dele a ser introduzida no conduto, o qual já havia sido lubrificado. Estando o pino em posição adequada, realizava-se a fotoativação durante 5 segundos, em cada uma das suas faces. Removia-se então este conjunto do conduto e complementava-se a fotoativação por 10 segundos, também em cada face. Detectada por análise visual, a falta de material era corrigida, repetindo-se o procedimento, até que se obtivesse uma perfeita "moldagem" do conduto. A aparência da porção radicular de um pino considerado adequado está ilustrada na figura 11.

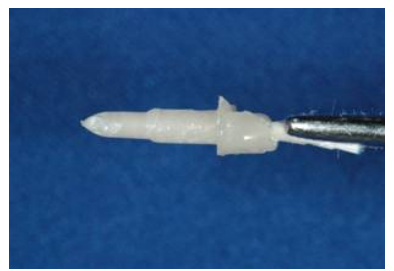

Figura 11 - Porção radicular de um pino considerado adequado.

Para a subseqüente confecção da porção coronária, a face oclusal da raíz era lubrificada e o pino era introduzido no conduto, quando então realizava-se, na porção coronária do pino, o tratamento adesivo já descrito. Após a lubrificação do interior e da face inferior da matriz coronária incolor, ela era preenchida por resina composta, ficando com a aparência ilustrada pela figura 12a. Após aplicar a resina também sobre o pino, esta era posicionada sobre aquele, tomando-se o cuidado em alinhar suas marcas, como descrito anteriormente; nesta ocasião, a aparência do conjunto está ilustrada pelas figuras 12b e 12c. Realizava-se então a fotoativação (a qual está ilustrada na figura 12d), durante 5 segundos, em cada uma das faces. A matriz era então removida da porção coronária do agora denominado núcleo anatômico, o qual era removido do conduto, para a eliminação dos excessos; pequenos defeitos eram corrigidos da forma já descrita. Eram igualmente conferidas suas dimensões; a extremidade superior do pino de fibra, visível na figura 12e, encontrava-se então na mesma altura da massa de resina, vindo a tocar na 
porção interna da futura coroa metálica; a aparência final de um dos núcleos deste grupo, pronto para a cimentação, pode ser vista na figura $12 f$.



Figura 12 - Matriz com resina no seu interior (a); seu alinhamento numa vista por lingual (b) e por proximal (c); momento da fotoativação inicial (d); pino no interior da resina (e) e um pino anatômico (f).

\subsection{Cimentação dos núcleos dos grupos NMF e ANATO.}

Cada um dos núcleos destes grupos era inicialmente limpo, da forma já descrita, com álcool etílico e manipulado através de uma pinça desde então.

Após a limpeza, toda a superfície radicular de cada núcleo do grupo ANATO foi submetida ao tratamento adesivo com o sistema Scotchbond MultiUso Plus, na forma já referida.

O conduto de cada raiz foi preenchido completamente com solução aquosa de EDTA a 24\% (Biodinâmica Química e Farmacêutica Ltda, Ibiporã PR), ali mantida durante 3 minutos, para desengorduramento e limpeza; a seguir foi feita a lavagem com água destilada, durante um minuto. A secagem foi iniciada por sucção, através de uma cânula comumente usada para tanto, e complementada com o auxílio de cones de papel absorvente comuns. Então, promoveu-se o condicionamento de sua superfície, com sol de ácido fosfórico a 37\% denominado Acid Gel (Dentsply Industria e Comércio Ltda, Petrópolis $\mathrm{RJ}$ ), aplicado durante 20 segundos, seguido de lavagem e secagem, efetuadas da forma já descrita. A seqüência de passos do tratamento adesivo do conduto foi realizada da mesma forma descrita para o núcleo do grupo ANATO e está ilustrada pelas Figuras 13a, 13b, 13c e 13d. 


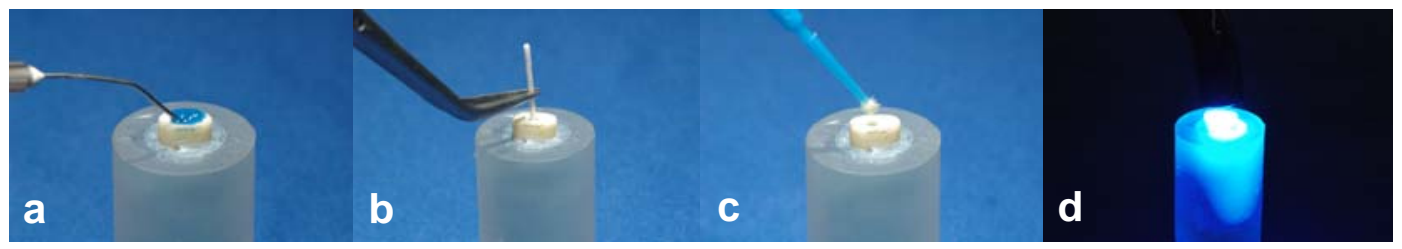

Figura 13 - Passos do tratamento adesivo do conduto: aplicação do sol (a), secagem do conduto (b), aplicação do adesivo (c) e fotoativação sendo realizada (d).

Em seguida, foi utilizado o Rely $X$ Luting 2, para cimentar os núcleos nas respectivas raízes. Para cada espécime, foram dispensadas quantidades iguais das respectivas pastas componentes do material (base e catalisadora), acionando-se uma única vez a alavanca do dispensador. Era então realizada a mistura delas, com o auxílio de uma espátula comum, até a obtenção de uma massa de cor uniforme, durante 30 segundos, de acordo com as orientações do fabricante. Uma pequena porção do cimento era aplicada, com auxílio de um pincel, na porção radicular do núcleo, e no interior do conduto, com uma broca Lentulo comum, adaptada a um contra-ângulo e girando em baixa rotação, no sentido anti-horário. O núcleo era então assentado no conduto, sob pressão digital, sendo então levado a uma prensa estática (figura 14a), onde era submetido à uma carga estática de 5 kgf, situação esta ilustrada pela figura 14b. Após cinco minutos, contados do início da mistura das pastas, eram eliminados seus excessos, com o auxílio de uma lâmina comum de bisturi; após mais cinco minutos, o conjunto era removido da prensa e realizava-se uma aferição da altura da porção coronária do núcleo (como está ilustrado pela Figura 14c), a qual deveria continuar com 5,5 mm. Assim, este conjunto estava apto para que sua coroa metálica fosse confeccionada.

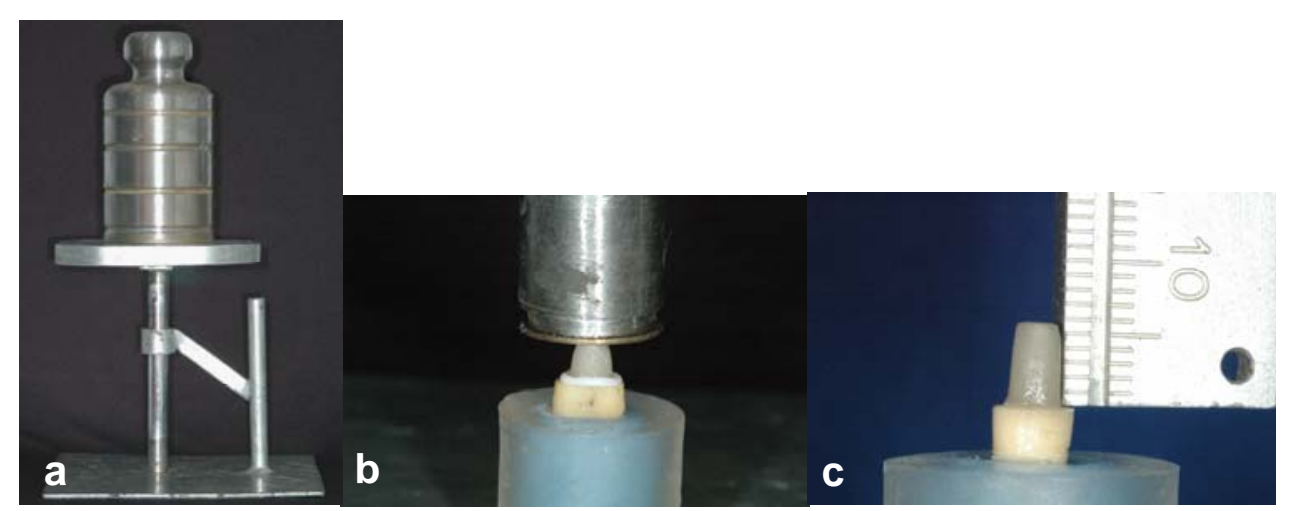

Figura 14 - Vista da prensa estática (a); um núcleo sendo cimentado (b) e a aferição da altura (c). 
Assim, os conjuntos estavam prontos para a confecção das respectivas coroas metálicas.

\subsection{Confecção dos núcleos do grupo PFFV.}

Neste grupo, existiram várias semelhanças com o anterior: foi utilizado o mesmo tipo de pino, tratado de forma idêntica, assim como a porção coronária foi confeccionada da mesma maneira. Entretanto, o pino era diretamente cimentado à raiz (numa posição central em relação ao conduto) com Rely $X$ Lutting 2, já no início da confecção do núcleo, após a limpeza e tratamento adesivo, tanto do conduto quanto do pino. Após a confecção da sua porção coronária, este era então considerado como núcleo e pronto para a etapa da fabricação da respectiva coroa.

\subsection{Confecção dos núcleos do grupo PFM.}

Nesse grupo, os procedimentos foram basicamente os mesmos descritos para o grupo anterior, porém com a utilização do pino de metal de $\mathrm{n}^{0}$ 064 (FKG Dentaire S. A., La Chaux-de-Fonds, Swiss), que têm 15 mm de comprimento e 1,3 mm de diâmetro, o qual não sofreu a aplicação do sistema adesivo.

\subsection{Confecção e cimentação das coroas totais metálicas.}

Estando prontos todos os núcleos dos 4 grupos, efetuava-se a fase de obtenção das respectivas coroas metálicas.

A porção coronária de cada núcleo era então lubrificada para que um dos casquetes de DuraLay, confeccionado previamente na cavidade do molde de silicona, fosse preenchido com esse mesmo material, em sua fase arenosa, sendo então pressionado sobre o núcleo, de forma a se obter um modelo para fundição. Após 10 minutos, o modelo era removido do núcleo e tinha seus excessos eliminados; este apresentava, em média, uma espessura de $2 \mathrm{~mm}$, em todas as suas regiões, e altura de $7 \mathrm{~mm}$. Nesta fase, cada modelo de resina recebeu um número de 1 a 10, dentro de cada um dos 4 grupos.

Após o processo de fundição, a face interna de cada coroa era usinada, da forma já referida, até que se mostrasse adequadamente adaptada ao respectivo núcleo, formando assim um espécime. 
Em cada uma das respectivas coroas foram então confeccionados 2 sítios de apoio, cada um deles com uma função diferente, como será descrito a seguir. Para tanto, um espécime era colocado na base do delineador, para que, na ponta da cúspide de sua coroa, uma faceta fosse criada, de maneira semelhante à do aplainamento da face superior das raízes dentárias (como está ilustrado pela figura 15a); este primeiro sitio serviria para aplicação de carga cíclica, no sentido do longo eixo dental.

A seguir, com o auxílio de uma ponta adiamantada esférica comum, penetrando metade do seu diâmetro na face lingual da coroa, foi confeccionado um nicho (da forma ilustrada pela figura 15b) que serviria para aplicação de carga progressiva, no sentido com inclinação de $45^{\circ}$ em relação ao longo eixo dental. Estes sítios (visíveis na figura 15c) permitiram padronizar o ponto de aplicação das cargas, nos diferentes espécimes.

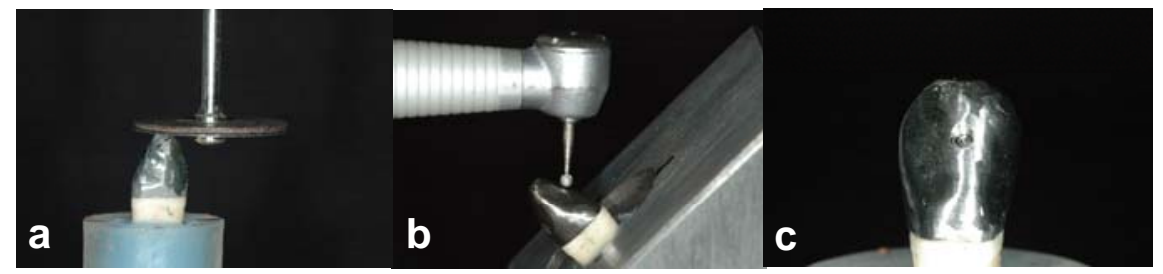

Figura 15 - Confecção da faceta incisal (a) e do nicho lingual (b); vista, por lingual, dos referidos sítios (c).

A limpeza da porção coronária de todos os núcleos foi efetuada, com álcool etílico, da forma já descrita. A seguir, com exceção dos espécimes do grupo NMF, todos os demais tiveram esta porção submetida ao tratamento com Scotchbond Multi-Uso Plus, já referido. A cimentação de cada coroa foi feita com Rely X Lutting 2 (como está ilustrado pela figura 16), de maneira semelhante àquela descrita para a cimentação dos núcleos dos grupos NMF e ANATO. Cada espécime foi então recolocado em seu respectivo frasco, onde permaneceu por um período de 24 horas, até ser submetido à ação da carga cíclica.

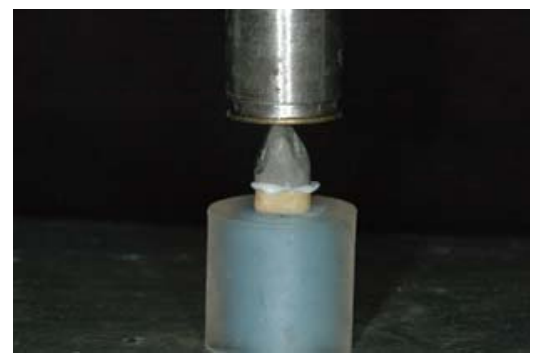

Figura 16 - Uma coroa, durante sua cimentação. 


\subsection{Aplicação da carga cíclica.}

Visando fazer com que cada espécime se aproximasse do estado de fadiga, foi utilizada a Máquina Eletro-Mecânica de Fadiga, localizada no Centro de Investigação e Pesquisa (CIP-1), da Faculdade de Odontologia de Bauru USP, para aplicar, na faceta incisal de cada coroa, uma carga que ia até $20 \mathrm{~N}$ (2 kgf), voltando a 0 , ciclo este repetido numa freqüência de $2 \mathrm{~Hz}$, por 250.000 vezes, num período de aproximadamente 35 horas. Como ilustrado pela figura $17 \mathrm{a}$, o aparelho permitia que esta aplicação fosse efetuada simultaneamente em 5 corpos-de-prova, os quais encontravam-se em posição vertical (formando um ângulo de $90^{\circ}$ com o plano horizontal), totalmente imersos em água deionizada, a uma temperatura de $37 \pm 1^{\circ} \mathrm{C}$. Ao final desse tratamento, nenhum componente (coroa ou núcleo), poderia ter se soltado de seus respectivos substratos, o que era aferido visualmente, com o auxílio de uma sonda clínica comum.

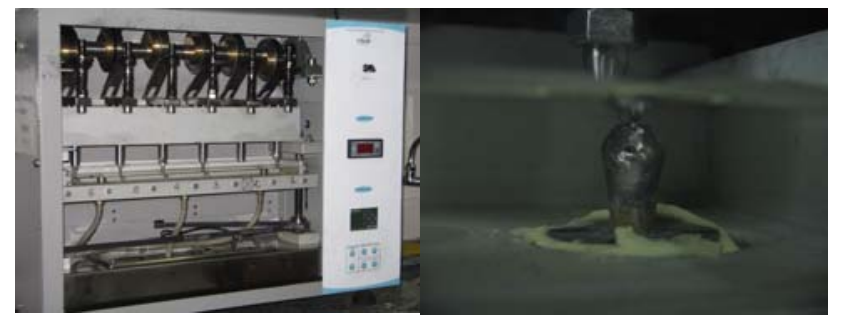

Figura 17 - Máquina utilizada para aplicação da carga cíclica (a), com detalhe da ponta aplicadora incidindo sobre a faceta incisal do corpo-de-prova.

\subsection{Ensaio de resistência à compressão.}

Finalmente, cada espécime foi submetido ao ensaio de compressão, até a fratura, em uma máquina universal de ensaios Kratos ${ }^{\circledR}$ (Kratos Dinamômetros Ltda. São Paulo - SP) recentemente calibrada, munida de uma célula de carga de $500 \mathrm{Kg}$ e regulada para desenvolver velocidade de 0,5 $\mathrm{mm} / \mathrm{min}$. A carga foi aplicada no nicho da face palatina da coroa, estando o espécime posicionado de forma que seu longo eixo recebesse a força de compressão incidindo a $45^{\circ}$, em relação ao longo eixo da raiz. Para tanto, um dispositivo metálico próprio permitia que o corpo-de-prova ficasse posicionado da forma referida, como está ilustrado pela figura 18. A máquina foi programada para que a aplicação da carga automaticamente cessasse, quando ocorresse alguma falha (soltura e/ou fratura) de qualquer uma das partes componentes do espécime. 


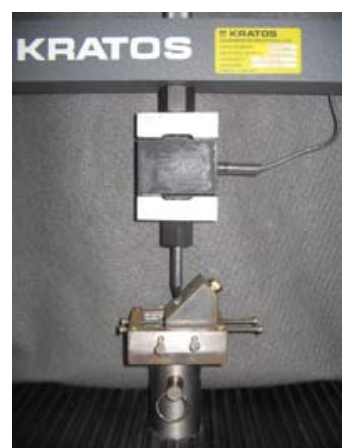

Figura 18 - Detalhe da máquina de ensaios, mostrando a ponta aplicadora da carga incidindo no nicho de um espécime fixado no dispositivo metálico posicionador.

Os valores da resistência à fratura ficavam registrados em arquivos do computador acoplado à máquina de ensaios, com os quais eram criados os respectivos gráficos. Os valores de carga de fratura foram submetidos ao tratamento estatístico, que consistiu numa análise de variância (a um critério, modelo fixo), seguida de um teste de Tukey, sempre com $p<0,5$. Numa planilha própria também era registrado o modo de fratura apresentado por cada espécime, anotando-se a localização e profundidade máxima da linha de fratura, medida esta última, com o auxílio de uma sonda periodontal comum; também era registrada a possibilidade do espécime fraturado vir a ser recuperado; o tipo de fratura era denominado como favorável, quando a linha se localizava desde 0 até $1 \mathrm{~mm}$ abaixo de um nível ósseo hipotético, ou desfavorável, quando ela ultrapassava este nível. 
5 - Resultados 



\section{5 - Resultados}

Os valores verificados (expressos em kgf) para cada espécime, dentro de cada grupo, no ensaio de resistência à fratura, são apresentados na Tabela 5.1, acompanhado da média, do desvio-padrão e do coeficiente de variância.

Tabela 5.1 - Valores da resistência (em kgf) de cada espécime dos 4 grupos estudados, com a média $(\mathrm{m})$, desvio-padrão (dp) e coeficiente de variância (cv), este expresso em porcentagem.

\begin{tabular}{|c|c|c|c|c|}
\hline \multirow{2}{*}{ Espécime } & \multicolumn{4}{|c|}{ Grupos } \\
\cline { 2 - 5 } & NMF & ANATO & PFFV & PFM \\
\hline 1 & 62,25 & 28,15 & $54,05>$ & 46,50 \\
\hline 2 & 58,40 & $53,20>$ & 34,68 & $51,55>$ \\
\hline 3 & 41,90 & 38,35 & $24,75<$ & 33,85 \\
\hline 4 & 62,45 & 25,35 & 26,33 & 45,50 \\
\hline 5 & $73,75>$ & 38,85 & 28,20 & 20,25 \\
\hline 6 & 29,57 & 13,80 & 28,20 & 18,42 \\
\hline 7 & 48,05 & 14,22 & 46,20 & $14,30<$ \\
\hline 8 & 27,77 & 33,60 & 43,15 & 29,55 \\
\hline 9 & $24,95<$ & $10,15<$ & 33,40 & 22,27 \\
\hline 10 & $\mathbf{n e})$ & 16,05 & 30,25 & $($ ne) \\
\hline $\mathbf{m}$ & $\mathbf{4 7 , 6 8}$ & $\mathbf{2 7 , 1 7}$ & $\mathbf{3 4 , 9 2}$ & $\mathbf{3 1 , 3 5}$ \\
\hline $\mathbf{d p}$ & $\mathbf{1 7 , 6 8}$ & $\mathbf{1 3 . 9 2}$ & $\mathbf{9 , 7 3}$ & $\mathbf{1 3 , 7 4}$ \\
\hline $\mathbf{c v}$ & $\mathbf{0 , 3 7}$ & $\mathbf{0 , 5 1}$ & $\mathbf{0 , 2 8}$ & $\mathbf{0 , 4 4}$ \\
\hline
\end{tabular}

ne - espécime não ensaiado, pois o conjunto coroa-núcleo se soltou da raiz, no ensaio cíclico.

$>$ - espécime com maior valor do grupo, neste ensaio.

<- espécime com menor valor do grupo, neste ensaio.

A respectiva análise de variância mostrou existir diferença significante entre os grupos estudados, com $f=3.74$, para $p<0,5$. A aplicação subseqüente de um teste de Tukey, também para $p<0,5$, permitiu a montagem da tabela 5.2 ; foi assim detectado que existiram diferenças significantes apenas entre os grupos NMF e ANATO.

Tabela 5.2 - Valores da resistência (em kgf) dos 4 grupos estudados, com a média (m) e a comparação entre os grupos.

$\begin{array}{lcc}\text { Grupo } & \text { Média } & \text { Comparação } \\ \text { ANATO } & 27.17 & \mathrm{a} \\ \text { PFFV } & 31.35 & \mathrm{a} \mathrm{b} \\ \text { PFM } & 34.92 & \mathrm{a} \mathrm{b} \\ \text { NMF } & 47.68 & \mathrm{~b}\end{array}$


Tabela 5.3 - Valores (expressos em $\mathrm{mm}$ ) referentes à profundidade da linha de fratura, em cada espécime dos 4 grupos estudados.

\begin{tabular}{|c|c|c|c|c|}
\hline Grupos & NMF & ANATO & PFFV & PFM \\
\hline $\mathbf{0 1}$ & -1 & -2 & -1 & -2 \\
\hline $\mathbf{0 2}$ & -2 & -1 & -2 & +1 \\
\hline $\mathbf{0 3}$ & -2 & 0 & +1 & -1 \\
\hline $\mathbf{0 4}$ & -2 & -2 & -2 & -1 \\
\hline $\mathbf{0 5}$ & 0 & +1 & +1 & -2 \\
\hline $\mathbf{0 6}$ & -1 & -2 & -1 & +1 \\
\hline $\mathbf{0 7}$ & -2 & -1 & -2 & -2 \\
\hline $\mathbf{0 8}$ & -1 & 0 & 0 & -2 \\
\hline $\mathbf{0 9}$ & 0 & -2 & -2 & -2 \\
\hline $\mathbf{1 0}$ & ne & -1 & -2 & ne \\
\hline
\end{tabular}

+ - localizada acima do nível ósseo simulado.

0 - nível ósseo simulado.

- - localizada abaixo do nível ósseo simulado

ne - espécime não ensaiado, pois o conjunto coroa-núcleo se soltou da raiz, no ensaio cíclico.

O grupo NMF apresentou linhas de fraturas que se localizavam desde o nível ósseo simulado até a profundidade de $2 \mathrm{~mm}$. Os grupos restantes apresentaram as mesmas profundidades em quase todas as fraturas, porém apresentaram, em média, 2 espécimes onde a fratura ocorreu $1 \mathrm{~mm}$ acima do nível ósseo simulado. Considerando-se que a fratura seja desfavorável quando a linha da fraturas está localizada abaixo do nível ósseo simulado, e como favorável quando localizada ao nível ou acima do nível ósseo simulado, onde seja possível manter o remanescente dentário na arcada.

Tabela 5.4 - Valores (em porcentagem) referentes à profundidade da linha de fratura, em cada espécime dos 4 grupos estudados.

\begin{tabular}{|c|c|c|c|c|}
\cline { 2 - 5 } \multicolumn{1}{c|}{} & NMF & ANATO & PFFV & PFM \\
\hline$+1 \mathrm{~mm}$ & 0 & 10 & 20 & 20 \\
\hline $\mathbf{0} \mathbf{~ m m}$ & 20 & 20 & 10 & 0 \\
\hline$-1 \mathrm{~mm}$ & 30 & 30 & 20 & 20 \\
\hline$-2 \mathrm{~mm}$ & 40 & 40 & 50 & 50 \\
\hline
\end{tabular}




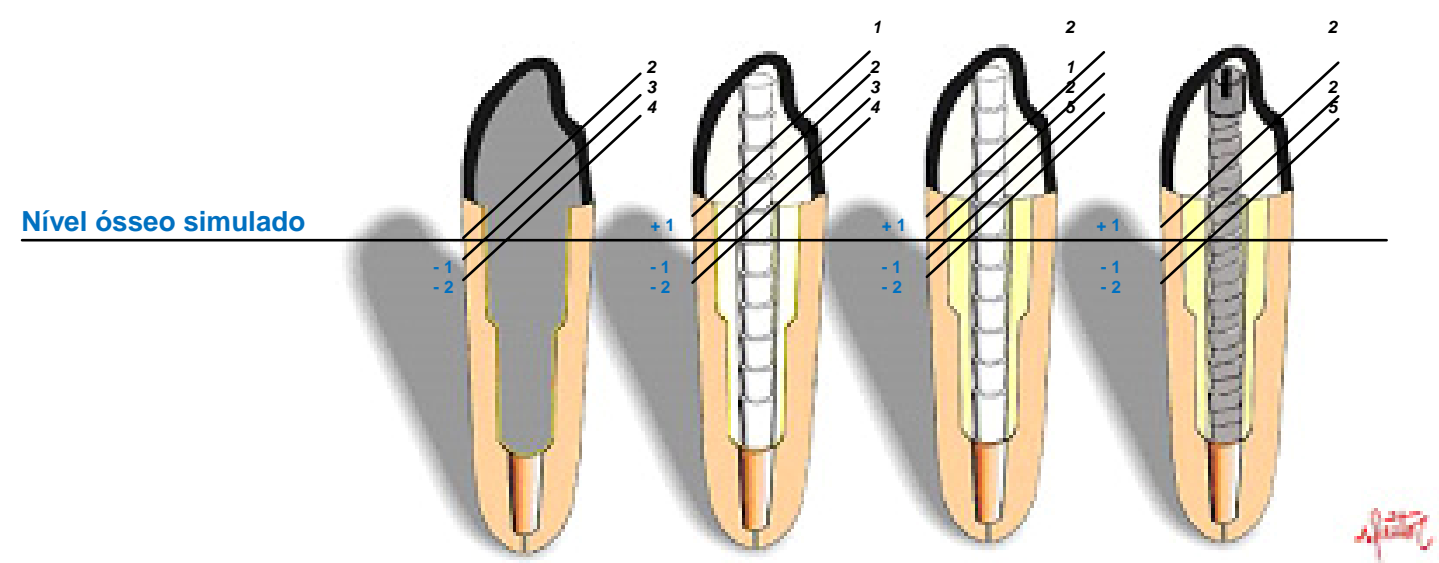

Figura 19 - Representação esquemática dos quatro grupos experimentais com seus respectivos níveis de fraturas (à partir da esquerda: NMF, ANATO, PFFV E PFM).

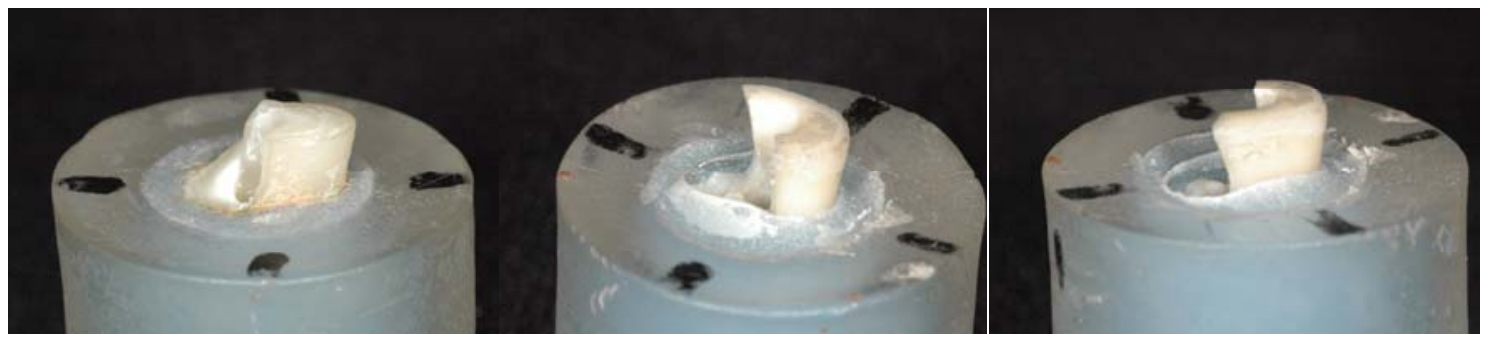

Figura 20 - Aparência de três remanescentes radiculares após o ensaio de fratura, já sem o núcleo, sem a coroa metálica e sem o fragmento fraturado, onde pode-se observar a profundidade da fratura localizada exatamente ao nível ósseo (a), $1 \mathrm{~mm}$ abaixo do nível (b) e $2 \mathrm{~mm}$ abaixo (c), sendo que estes dois últimos remanescentes, foram descritos na literatura como impossíveis de serem reparados. 
6 - Discussão 



\section{6 - Discussão}

\section{Aspectos gerais.}

As técnicas utilizadas na restauração de dentes que sofreram a perda da sua porção coronária têm sido modificadas e melhoradas com o passar do tempo, de acordo com pesquisas realizadas in vitro e in vivo. Estes dentes necessitam, inevitavelmente, de tratamento endodôntico que deve ser realizado de forma a preservar estrutura, sendo removida somente a dentina infectada e eliminadas as áreas de retenção mecânica, segundo CHEN et al. ${ }^{12}$. O uso de pinos intraradiculares é indicado após tratamento endodôntico, quando se tem uma grande quantidade de estrutura remanescente coronária, na ausência desta ou quando os condutos radiculares foram mediana ou excessivamente alargados, segundo GOTO et al. $^{28}$, NAUMANN; PREUSS; FRANKENBERGER ${ }^{50}$, PEROZ et al. ${ }^{53}$ e SALVI et al. $^{57}$. Porém, como há um grande número de pinos de diferentes materiais no mercado, a sua indicação deve ser muito bem estudada, assim como as técnicas que serão empregadas, o cimento utilizado para a fixação dos pinos, a confecção da porção coronária e da coroa, segundo $\mathrm{HU}$ et al. ${ }^{37}$, os diferentes materiais utilizados para cada uma dessas partes e, quando da realização de estudos em laboratório, a seleção do tipo de ensaio relacionado à resistência à fratura.

A razão de se utilizar coroas totais se dá pela modificação da distribuição das cargas funcionais, sendo que estas se concentram na porção cervical do remanescente radicular, de acordo com ASSIF e GORFIL ${ }^{2}$. Possivelmente, o início de uma fratura ocorra numa das regiões cervicais proximais, pela razão de um preparo inadequado do conduto e/ou protético, fratura essa que estende-se para uma região do terço médio radicular da face vestibular, como o ocorrido em todos os corpos-deprova ensaiados.

\section{Padronização do preparo intra-radicular.}

Os dentes tratados endodonticamente apresentam uma diminuição da sua capacidade de absorção e transmissão das tensões, provenientes dos contatos oclusais. A remoção excessiva de dentina durante a instrumentação causa o enfraquecimento das paredes, tornando o dente mais susceptível à fratura, segundo CHEN et al. ${ }^{12}$. Pela razão de neste estudo ser analisado o desempenho dos condutos descritos como medianamente alargados, o preparo destes foi realizado de forma padronizada, utilizando-se brocas semelhantes àquelas utilizadas nos estudos 
anteriores de ZOGHEIB $^{66}$ E FRANCO ${ }^{23}$, fixadas a um motor, sendo então este conjunto broca/motor adaptado a um delineador (ou paralelômetro) que impedia a movimentação horizontal deste conjunto, prevenindo a ocorrência de desgaste nesse sentido (ou de forma sinuosa), anulando assim a possibilidade de se confeccionar áreas de retenção mecânica. O preparo, já descrito anteriormente, foi desenvolvido para este estudo, pois nenhum outro descreveu alguma técnica que permitisse padronizar as dimensões dos condutos.

\section{Tipos de pinos.}

Muitos trabalhos afirmam que o uso de núcleos fundidos em metal, por razão de seu baixo módulo de elasticidade, pode causar eventuais fraturas do remanescente radicular levando à perda do elemento. Essas fraturas ocorrem nos terços médios e apicais das raízes, muitas vezes acompanhando o sentido do longo eixo dental. Tal fato também é relatado, quando do uso de pinos constituídos por cerâmicas, como os de dióxido de zircônio. Por isso, a remoção excessiva de estrutura dentária para se conseguir um melhor acesso ao conduto ou pela aplicação de uma técnica, quando se utiliza um conjunto de instrumentos de um determinado fabricante, onde não se pode desgastar menos estrutura sadia, por utilizar-se um pino bastante volumoso, segundo MATTISON $^{45}$, pode causar o afinamento das paredes circundantes radiculares, tornando-as susceptíveis à fratura.

Contrariando alguns autores (BACHICHA et al. ${ }^{3}$, SCOTTI e FERRARI ${ }^{58}$, GOTO et al. ${ }^{28}$ e SAHAFI et al. ${ }^{56}$ ) que contra-indicam a utilização dos núcleos fundidos em metal na restauração de raízes que apresentem condutos medianamente alargados, o presente trabalho apresentou resultados favoráveis ao uso deste tipo de pino, principalmente pela razão de que, mesmo apresentando fraturas consideradas desfavoráveis, semelhantes àquelas encontradas em todos os grupos estudados, a carga necessária para que se ocorresse tal fratura foi considerada a mais alta de todas, com média de $47 \mathrm{~kg}$, sendo a máxima registrada em $73 \mathrm{~kg}$. Cargas semelhantes àquela encontrada como a média, foram observada, em um estudo sobre força de mordida, quando do apertamento realizado por dentes molares antagonistas, encontrando-se uma média de $40 \mathrm{~kg}$ para mulheres e $58 \mathrm{Kg}$ para homens, de acordo com um estudo realizado por BREKHUS et al. ${ }^{10}$. Com base neste estudo, os resultados do presente trabalho são considerados como aceitáveis.

Os pinos pré-fabricados metálicos, reforçados por fibra de vidro, fibra de carbono, quartzo, polietileno e dióxido de zircônio, associados aos atuais sistemas adesivos, permite o profissional realizar os procedimentos restauradores de um 
remanescente dental em uma só sessão clínica. Porém, aqueles constituídos por polietileno sempre apresentaram resultados inferiores, quando comparados com qualquer outro tipo de pino, nos ensaios de resistência à fratura. Já os pinos constituídos por quartzo e dióxido de carbono apresentam extrema rigidez, transmitindo toda e qualquer tensão diretamente ao remanescente radicular, sendo encontrados relatos de fraturas do tipo desfavorável, quando do uso destes, embora ainda utilizados em estudos. Os constituídos de fibra de carbono e de vidro têm sido os mais estudados na atualidade, segundo BATEMAN; RICKETTS; SAUNDERS ${ }^{6}$, porém, o de fibra de vidro reúne muitas características descritas como ideais, sendo algumas delas uma adequada adesão ao cimento e às resinas (como na cimentação diretamente à raiz ou na confecção de um "pino anatômico", segundo GRANDINI ${ }^{31}$ ), o módulo de elasticidade semelhante ao da dentina, a facilidade de realizar a técnica empregada em seu uso, possibilidade de se realizar a restauração em sessão única (HEYDECKE e PETERS ${ }^{35}$ ) e, caso ocorra algum comprometimento do conjunto coroa/porção coronária/pino/raiz, sua remoção é facilitada pela baixa resistência ao desgaste, permitindo a resolução do problema de forma rápida e fácil, sendo então restaurado posteriormente (FERNANDES; SHETTY; COUTINHO ${ }^{19}$, GRANDINI ${ }^{31}$, GRANDINI; SAPIO; SIMONETTI ${ }^{30}$ ). Com base nos resultados encontrados, a restauração dos remanescentes pode ser realizada de forma tradicional, sendo o pino pré-fabricado metálico ou o reforçado por fibra de vidro cimentado diretamente no conduto, o que torna o procedimento mais rápido, por ser realizado em sessão única e confiável, por apresentarem as médias, respectivamente, de 34 e $31 \mathrm{~kg}$. A utilização de um "pino anatômico" na restauração de um remanescente, além de ser mais trabalhosa pela razão da necessidade de se moldar o conduto com a resina, apresentou ou resultados mais baixos deste estudo, com a média de $27 \mathrm{~kg}$, contrariando estudos anteriores de GRANDINI ${ }^{31}$ e GRANDINI; SAPIO; SIMONETTI ${ }^{30}$.

\section{Cimentação.}

O propósito deste estudo não foi o de avaliar os diferentes tipos de cimentos encontrados no mercado, embora STANDLEE; CAPUTO; HANSON ${ }^{62}$ terem relatado que somente há necessidade da se estudar vários tipos de cimento quando da utilização de pinos de formato cônico, porém, o cimento de ionômero de vidro modificado por resina, que apresenta dupla polimerização foi o selecionado pela razão dos relatos de vários autores que a fotoativação não é efetiva, ou seja, a luz não consegue atingir, com intensidade necessária, o terço médio e apical do conduto 
radicular, não polimerizando o cimento de maneira adequada. Este cimento demonstrou ser aceitável para o presente de estudo, pois dos 40 corpos-de-prova ensaiados, somente 2 conjuntos pino/coroa se soltaram do seu remanescente radicular, sendo que nenhuma dessas coroas se soltou de seu respectivo pino. SCOTTI e FERRARI ${ }^{58}$, relataram que quando as forças oclusais ultrapassam o limite elástico do remanescente, há perda de adesão entre o cimento e as paredes do conduto causando a soltura do pino.

Utilizou-se somente uma combinação sistema adesivo/cimento para todos os corpos-de-prova deste estudo, pois segundo o trabalho de STANDLEE; CAPUTO; HANSON $^{62}$, a variação do tipo de cimento utilizado parece ter uma influência muito pequena, quase que desprezível, quando se estuda resistência à fratura.

\section{Confecção da porção coronária}

A confecção desta porção também foi realizada de forma padronizada, com o auxílio de uma matriz de resina acrílica, confeccionada sobre a porção coronária do primeiro núcleo fundido em metal, permitiu que, após a confecção da porção coronária de todos os corpos-de-prova, todas elas apresentassem as mesmas dimensões daquela primeira. O uso desta matriz foi baseado nos recentes trabalhos realizados por ZOGHEIB ${ }^{66}$ e FRANCO ${ }^{23}$, onde se estudou a resistência à fratura de raízes que sofreram tratamento endodôntico, porém a técnica de confecção desta foi modificada, sendo a matriz confeccionada com um material rígido, não permitindo nenhuma distorção quando da confecção desta porção.

Não houve nenhuma fratura envolvendo a porção coronária de nenhum corpode-prova, tampouco a perda de adesão desta em relação à face oclusal do remanescente radicular ou em relação ao pino.

\section{Ensaios.}

O carregamento realizado de forma cíclica é relatado, por vários autores como ESHELMAN e SAYEGH ${ }^{17}$, MANNOCCI; FERRARI; WATSON ${ }^{44}$, JUNG et al. ${ }^{39}$, como sendo uma situação mais próxima daquela encontrada no meio bucal, quando realizado na face palatina das coroas formando um ângulo de $45^{\circ}$ em relação ao longo eixo dental. Porém, por motivos de conveniência, neste estudo foi realizada a aplicação da carga cíclica em um nicho incisal, de forma que esta incidisse no sentido do longo do eixo dental. Os critérios para a seleção da quantidade de ciclos foram baseados nos trabalhos de MANNOCCl; FERRARI; WATSON ${ }^{44}$, HEYDECKE et al. $^{34}$, GOTO et al. ${ }^{28}$, JUNG, et al. ${ }^{39}$ sendo selecionado o total de 250.000 ciclos, 
pois não se tem a intenção de que os corpos-de-prova sejam fraturados durante a ciclagem e sim, a intenção de uma simulação de mastigação, promovendo ou não algum enfraquecimento destes. Esta simulação podia ser realizada por razão da freqüência de $2 \mathrm{~Hz}$ programada na máquina de ensaios a qual corresponde, aproximadamente, à freqüência média encontrada em uma mastigação natural, segundo MANNOCCl; FERRARI; WATSON ${ }^{44}$, HEYDECKE et al. ${ }^{34}$.

Nos ensaios onde uma carga vertical era progressivamente aumentada até que se ocorresse a fratura do corpo-de-prova, os dentes foram posicionados em ângulo de $45^{\circ}$ para a possível simulação do ângulo de contato encontrado no padrão oclusal de Classe I de Angle, entre os dentes ântero-superiores e inferiores, de acordo com os estudos de ZOGHEIB $^{66}$ e FRANCO ${ }^{23}$.

\section{Dos resultados.}

Com base nos resultados de resistência à fratura de todos os corpos-de-prova, aqueles pertencentes ao grupo NFM apresentaram a maior média do estudo, sendo ela de 47,68 kg, onde o maior registro (deste grupo e do estudo, em geral) foi de $73,75 \mathrm{~kg}$ e o menor de 24,95 $\mathrm{kg}$. As fraturas encontradas em 2 dos espécimes neste grupo estavam localizadas no mesmo nível daquele ósseo simulado; em 4 espécimes a fratura estava $1 \mathrm{~mm}$ abaixo desse e, nos 4 restantes, $2 \mathrm{~mm}$ abaixo. Somente os 2 corpos-de-prova em que as fraturas ocorram ao mesmo nível da simulação óssea foram caracterizados como favoráveis, ou reparáveis. Os outros 8 foram caracterizados como desfavoráveis, ou irreparáveis, pois a profundidade das fraturas alcançou níveis de $1 \mathrm{~mm}$ abaixo daquele da simulação, em 4 destes espécimes, e 2 $\mathrm{mm}$ abaixo para os outros 4 .

O grupo ANATO apresentou a média de $27,17 \mathrm{~kg}$, sendo a mais baixa dentre todos os grupos. A maior carga registrada foi a de $53,20 \mathrm{~kg}$ e a menor (deste grupo e do estudo, em geral) foi a de 10,15 $\mathbf{k g}$. Somente 1 dos corpos-de-prova apresentou a fratura do tipo favorável. Em 2 deles, foram encontradas fraturas ocorridas ao mesmo nível do simulado ósseo. Nos 7 restantes, foram encontradas fraturas desfavoráveis, sendo que 3 delas estavam $1 \mathrm{~mm}$ abaixo do nível ósseo e, 4 estavam 2 $\mathrm{mm}$ abaixo deste.

No grupo PFFV a média encontrada foi a de $34,92 \mathrm{~kg}$, sendo que a máxima carga registrada foi de 54,05 kg e a mínima foi de $24,75 \mathrm{~kg}$. Em relação às fraturas, 2 espécimes apresentaram fraturas favoráveis, localizadas $1 \mathrm{~mm}$ acima do nível ósseo e 1 apresentou a fratura ao mesmo deste. Foram encontradas 7 fraturas desfavoráveis, sendo 2 ocorridas a $1 \mathrm{~mm}$ abaixo do nível ósseo e 5 delas ocorridas $2 \mathrm{~mm}$ abaixo deste. 
O grupo PFM apresentou a média de $31,35 \mathrm{~kg}$, sendo muito próxima daquela encontrada no grupo PFFV. A maior carga registrada foi de $51,55 \mathrm{~kg}$ e a menor foi de 14,30 kg. Foram encontradas fraturas favoráveis em 2 espécimes, localizadas $1 \mathrm{~mm}$ acima do nível ósseo. As fraturas desfavoráveis foram encontradas em 8 espécimes, sendo 3 delas localizadas $1 \mathrm{~mm}$ abaixo do nível ósseo e, 5 delas localizadas $2 \mathrm{~mm}$ abaixo do nível ósseo.

Não houve diferença estatisticamente significante entre os grupos NMF, PFFV e PFM. Tampouco houve diferença entre os grupos PFFV, PFM e ANATO. Porém, houve diferença entre os grupos NMF e ANATO.

Com base neste estudo, a quantidade de carga necessária para que ocorra a fratura do remanescente radicular de um elemento canino superior (quando seu conduto sofrer mediano alargamento e, for restaurado com os tipos de pinos estudados, a exceção dos "pinos anatômicos") é maior do que aquela suportada por eles. Portanto, seria indicada a restauração de remanescentes radiculares de dentes ântero-superiores e inferiores com núcleos fundidos em metal, pinos pré-fabricados em fibra de vidro e em metal. Pode-se dizer, também que, em restaurações onde se utilizem pinos "anatômicos" e os pré-fabricados em fibra de vidro, caso ocorra alguma fratura, temos $30 \%$ de chance de que essas ocorram acima do nível ósseo, possibilitando assim seu reparo.

Ainda estamos distantes de uma solução $100 \%$ confiável, no que diz respeito a restaurações de elementos com condutos medianamente alargados. Quando um conjunto suporta grandes forças, geralmente, quando se ocorre algum tipo de fratura, esta é desfavorável. Quando as características (como módulo de elasticidade, coeficientes de expansão e contração térmica) dos materiais empregados neste estudo foram semelhantes àquelas dos elementos dentários, os conjuntos não suportaram grandes cargas compressivas. Porém, procedimentos clínicos, como extrusão dentária ortodôntica e/ou aumento de coroa, nos permitem restaurar elementos que sofreram a perda de suas distâncias biológicas. Cada um destes procedimentos deve ser muito bem indicado, por razão de áreas onde a estética seja necessária, não havendo, assim, nenhum desequilíbrio da harmonia natural

Por isso, se faz necessária a realização de novos estudos comparando as técnicas e materiais encontrados no mercado, na tentativa de reparar adequadamente os remanescentes radiculares que se tornaram frágeis por algum motivo. 
7 - Conclusões 



\section{7 - Conclusões}

Através da realização deste estudo e após aplicação da análise estatística sobre os valores obtidos, pôde-se concluir que:

1. A resistência à fratura sob carga compressiva não mostrou diferença estatisticamente significante entre os remanescentes reconstruídos com núcleos metálicos fundidos, pinos pré-fabricados em fibra de vidro e em metal. Houve diferença estatisticamente significativa somente entre os remanescentes reconstruídos com núcleos metálicos fundidos e com "pinos anatômicos". Os remanescentes reconstruídos com núcleos metálicos fundidos suportaram as maiores cargas, enquanto que os que receberam "pinos anatômicos" foram os menos resistentes.

2. Os remanescentes reconstruídos com núcleos metálicos fundidos e pinos pré-fabricados em metal, apresentaram $80 \%$ das fraturas desfavoráveis. Os remanescentes reconstruídos com "pinos anatômicos" e pinos pré-fabricados em fibra de vidro, apresentaram $30 \%$ das fraturas favoráveis ao reparo. 

Referências

bibliográficas 



\section{Referências bibliográficas}

1. Al-Hazaimeh N, Gutteridge DL. An "in vitro" study into the effect of the ferrule preparation on the fracture resistance of crowned teeth incorporating prefabricated post and composite core restorations. International Endodontic Journal 2001 34:40-6.

2. Assif D, Gorfil C. Biomechanical considerations in restoring endodontically treated teeth. J Prosthet Dent. 1994 Jan:71(6):565-7.

3. Bachicha WS, Difiore PM, Miller DA, Lautenschlager EP, Pashley DH. Microleakage of endodontically treated teeth restored with posts. J Endod. 1998 Nov;24(11):703-8.

4. Baraban DJ. Immediate restoration of pulpless teet. J Prosthet Dent. 1972 28:607-12.

5. Baraban DJ. The restoration of pulpless teeth. Dent Clin N Am, p.633-53, Nov. 1967.

6. Bateman G, Ricketts DN, Saunders WP. Fibre based post systems: a review. Br Dent J, 195:1: 43-8, July 2003.

7. Black GV. A method of grafting artificial crowns on roots of theet. Mo. Dent. J. 1869, 1, 233-6. In: Morgano, S. M., Brackett, S. E. Foundation restorarions in fixed prosthodontics: current knowledge abd future needs. $\mathrm{J}$ Prosthet Dent. 1999 82: 643-57.

8. Bottino MA, Quintas AF, Miyashita E, Giannini V. Núcleos, In: Estética em Reabilitação Oral: Metal Free. Capítulo 3, pág. 67-123, 1ª ed., Ed. Artes Médicas, São Paulo, 2001.

9. Bouillaguet S, Troesch S, Wataha JC, Krejci I, Meyer JM, Pashley DH. Microtensile bond strength between adhesive cements and root canal dentin. Dent Mater. 2003 May;19(3):199-205.

10. Brekhus PJ, Armstrong WD, SIMON WJ. Stimulation of the muscles of mastication' Minneapolis J Dent Res.1940 Dec:17(7):292.

11. Butz F, Lennon AM, Heydecke G, Strub JR. Survival rate and fracture strength of endodontically treated maxillary incisors with moderate defects restore with different post and core systems: an in vitro study. Int J Prosthodont, 2001 14(1):58-64.

12. Chen J, Yue L, Wang JD, Gao XJ. The correlation between the enlargement of root canal diameter and the fracture strength and the stress distribution of root. Zhonghua Kou Qiang, Yi Xue Za Zhi. 2006 Nov;41(11):6613. 
13. Cury AH, Goracci C, De Lima Navarro MF, Carvalho RM, Sadek FT, Tay FR. Effect of hygroscopic expansion on the push-out resistance of glass ionomer-based cements used for the luting of glass fiber posts. J Endod. 2006 Jun;32(6):537-40.

14. Demas, NC. Direct impression for cast Richmond crown using acetate crowns forms. Dental Diag. 1957 63;258-9.

15. Duret B, Reynaud M, Duret F. Un nouveau concept de reconstituction corono-radiculaire: le Composipost (1). Le Chir Dent de France, 540, 131-41, 1990.

16. Duret B, Reynaud M, Duret F. Un nouveau concept de reconstituction corono-radiculaire: le Composipost (2). Le Chir Dent de France, 542, 69-77, 1990.

17. Eshelman EG; Sayegh FS. Dowel materials and root fracture. J Prosthet Dent. 1983 Sept:50(3):342-4.

18. Fauchard P. Lê Chiqurgien Dentiste, ou Traite des dents. Tome premier, Avec Approbations \& Privilége du Roi, Paris, 1746.

19. Fernandes AS, Shetty S, Coutinho I. Factors determining post selection. J Prosthet Dent. 2003 Dec:90(6)556-62.

20. Ferrari M, Vichi A, Mannocci F, Mason PN. Retrospective study of the clinical performance of fiber posts. Am J Dent. 2000 May:12:9B-13B Special issue.

21. Ferrari M, Mannocci F, Vichi A, Cagidiaco MC, Mjor IA. Bonding to root canal: structural characteristics of the substrate. Am J Dent. 2000 Oct;13(5):255-60.

22. Ferrari M, Mannocci F. A 'one-bottle' adhesive system for bonding a fibre post into a root canal: an SEM evaluation of the post-resin interface. Int Endod J. 2000 Jul;33(4):397-400.

23. Franco, E. C. Avaliação da resistência à fratura de dentes tratados endodonticamente restaurados com pinos de fibra de vidro variando o seu comprimento intracanal [tese]. Bauru (SP): Faculdade de Odontologia de Bauru, Universidade de São Paulo; 2006.

24. Freedman G. The carbon fiber post: metal-free, post-endodontic rehabilitation. Oral Health, Don Mills, 1996 Feb:86(2)23-30.

25. Freilich MA, Meiers JC, Duncan JP, Goldberg AJ. Fiber-reinforced composites in clinical dentistry. Quintessence Int. 2000. 106 p.

26. Goldberg AJ, Burstone CJ. The use of continuous fiber reinforcement in dentistry. Dent Mater, 1992 May;8(3):197-202. 
27. Goracci C, Fabianelli A, Sadek FT, Papacchini F, Tay FR, Ferrari M. The contribution of friction to the dislocation resistance of bonded fiber posts. $\mathrm{J}$ Endod. 2005 Aug;31(8):608-12.

28. Goto Y, Nicholls JI, Phillips KM, Junge T. Fatigue resistance of endodontically treated teeth restored with three dowel-and-core systems. J Prosthet Dent. 2005 Jan;93(1):45-50.

29. Grandini S, Ferrari MI. Perni anatomici. II Dentista Moderno, 97-102, 2000.

30. Grandini S, Sapio S, Simonetti M. Use of anatomic post and core for reconstructing an endodontically treated tooth: a case report. J Adhes Dent. 2003 5(3);243-7.

31. Grandini S. O pino anatômico. In: SCOTTI, R.; FERRARI, M. (Coord). Pinos de fibra. São Paulo: Artes Médicas, 2003. Cap. 9:93-8.

32. Hampson EL, Clark J. The post-retained crown. Dent. Pract. Dent. Rec., 8;130-5, 1958.

33. Hayashi M, Takahashi $\mathrm{Y}$, Imazato S, Ebisu S. Fracture resistance of pulpless teeth restored with post-cores and crowns. Dent Mater. 2006 May;22(5):477-85.

34. Heydecke G, Butz F, Hussein A, Strub JR. Fracture strength after dynamic loading of endodontically treated teeth restored with different post-andcore systems. J Prosthet Dent. 2002 Apr:87(4):438-45.

35. Heydecke G, Peters MC. The restoration of endodontically treated, single-rooted teeth with cast or direct posts and cores: a systematic review. J Prosthet Dent. 2002 Apr;87(4):380-6.

36. Holmes DC, Diaz-Arnold AM, Leary JM. Influence of post dimension on stress distribuition in dentin. J Prosthet Dent. 1996 Feb:75(2)140-7.

37. Hu Y; Pang I, Hsu C, Lau Y. Fracture resistance of endodontically treated anterior restored with four post-and-core systems. Quint Inter, 2003 May:34(5):349-53.

38. Hudis SI, Goldstein GR. Restoration of endodontically treated teeth: a review of the literature. J Prosthet Dent. 1986 Jan:55(1):33-8.

39. Jung SH, Min KS, Chang HS, Park SD, Kwon SN, Bae JM. Microleakage and fracture patterns of teeth restored with different posts under dynamic loading. J Prosthet Dent. 2007 Oct; 98(4):270-6. 
40. Kovarik RE, Breeding LC, Caughman WF. Fatigue life of three core materials under simulated chewing conditions. J Prosthet Dent. 1992 Oct:68(10):584-90.

41. Lowell, M. J. The bond between CFRC and restorative materials. MS Thesis, Univesity of London, 1983.

42. Lui JL. A technique to reinforce weakened roots with post canals. Case report. Endod. Dent. Traumatol, 1987 3:310-14.

43. Lui JL. Composite resin reinforcement of flared canals using lighttrasmitting plastic posts. Quintessence International, 1994 25:313-19.

44. Mannocci F, Ferrari M, Watson T. Intermittent loading of teeth restored using quartz fiber, carbon-quartz fiber and zirconium dioxide ceramic root canal posts. J Adhes Dent, 1999 1(2):153-8.

45. Mattison GD. Photoelastic stress analysis of cast-gold endodontic posts. J Prosthet Dent. 1982 Oct:48(4):407-11.

46. Mendoza DB, Eakle WS, Kahl EA, Ho R. Root reinforcement with a resinbonded preformed post. J. Prosthet Dent. 1997 78:10-5.

47. Mondelli J, Steagall L, Ishikiriama A, Navarro MFL, Soares FB. Fracture strength of human teeth with cavity preparations. J Prosthet Dent.1980 Apr:43(4):419-22.

48. Monticelli F, Grandini S, Goracci C, Ferrari M. Clinical behavior of translucent-fiber posts: a 2-year prospective study. Int J Prosthodont. 2003 NovDec;16(6):593-6.

49. Morgano SM, Brackett SE. Foundation restorarions in fixed prosthodontics: current knowledge and future needs. J Prosteht Dent. 1999 82:643-57.

50. Naumann M, Preuss A, Frankenberger R. Reinforcement effect of adhesively luted fiber reinforced composite versus titanium posts. Dent Mater. 2006 Feb 4.

51. Newman MP, Yaman P, Dennison J, Rafter M, Billy E. Fracture resistance of endodontically treated teeth restored with composite posts. J Prosthet Dent. 2003 Apr:89(4):360-7.

52. Pegoraro LF, Valle AL, Araújo CRP, Bonfante G, Conti PCR, Bonachela V. Núcleos. In: Prótese Fixa. São Paulo, Artes Médicas, p. 85110, 1998.

53. Peroz I, Blankenstein F, Lange KP, Naumann M. Restoring endodontically treated teeth with posts and cores--a review. Quintessence Int. 2005 Oct;36(9):737-46. 
54. Pontius O, Hutter J. Survival and fracture strength of incisors restored with different post and core systems and endodontically treated incisors without corono-radicular reinforcement. J Endod. 2002 Oct:28(10):710-15.

55. Robbins JW. Restoration of the endodontically treated tooth. Dent Clin North Am. 2002 Apr;46(2):367-84.

56. Sahafi A, Peutzfeldt A, Ravnholt G, Asmussen E, Gotfredsen K. Resistance to cyclic loading of teeth restored with posts. Clin Oral Investig. 2005 Jun;9(2):84-90.

57. Salvi GE, Siegrist Guldener BE, Amstad T, Joss A, Lang NP. Clinical evaluation of root filled teeth restored with or without post-and-core systems in a specialist practice setting. Int Endod J. 2007 Mar;40(3):209-15.

58. Scotti R, Ferrari M. Pinos de Fibra: Considerações Teóricas e Aplicações Clínicas. São Paulo: Artes Médicas; 2002.

59. Sorensen JA, Engelman MJ. Effect of post adaptation on fracture resistance of endodontically treated teeth. J Prosthet Dent. 1990 Oct:64(4):41924.

60. Sorensen JA, Engelman MJ. Ferrule design and fracture resitance of endodontically treated teeth. J Prosthet Dent. 1990 63:529-36.

61. Spalten RG. Composite resins to restore multilated teeth. J Prosthet Dent, 1971 25:323-6.

62. Standlee JP, Caputo AA, Hanson EC. Retention of endodontic dowels: effects of cement, dowel length, diameter and design, J Prosthet Dent. 1978 Apr:39(4):401-5.

63. Stockton LW. Factors affecting retention of post system: A literature review. J Prosthet Dent. 1999 Apr:81(4):380-5.

64. Torbjorner A, Fransson B. A literature review on the prosthetic treatment of structurally compromised teeth. Int J Prosthodont. 2004 17:369-76.

65. Virgil MS, Lau BS. The reinforcement of endodontically treated teeth. Dental Clinics of North America 1976 Apr:20(2).

66. Zogheib LV. Resistência à fratura de dentes tratados endodonticamente restaurados com pinos de fibra de vidro quando submetidas a testes de ciclagem dinâmica e estática [tese]. Bauru (SP): Faculdade de Odontologia de Bauru, Universidade de São Paulo; 2005. 
Abstract 


\section{Abstract}

Evaluation of the fracture strength of endodontically treated teeth, reconstructed with post and cores, when submitted to the dynamic loading.

In this study, was evaluated the strength of endodontically treated teeth, had been reconstructed with a crown of $\mathrm{NiCr}$ alloy (Verabond II), which was supported by a post and core for different materials, gotten for different techniques, cemented in the root with the glass ionomer Rely $X$ Lutting 2 , which is increased of composed resin. These diferents post and cores were of the casting metallic type, in group NMF; in group ANATO, the composed resin Filtek Z250 (3M ESPE, St. Paul-MN, USA) was the core, contend a glass fiber post (Reforpost Fibra de Vidro RX, Ângelus Indústria de Produtos Odontológicos Ltda., Londrina - PR); this exactly type of post was used in group PFFV, being directly cemented, without resin addition on the core; finally, in group PFM, a metallic post (064, FKG Dentaire S. , La Chaux-of-Fonds, Swiss) were cemented in the same way described for the previous group. All the roots were proceeding from maxillary human canines, randomly distributed, thus composing the four groups, each one with 10 specimens: The specimens, after 24 hours of the cimentation, had been submitted the cyclical efforts, in an Electromechanical Machine of Fatigue, applied in the direction of the long dental axle, with load of $20 \mathrm{~N}$, in the frequency of $2 \mathrm{~Hz}$, thus occuring a total of 250.000 cycles. Excepting 2 body-of-test whose post and cores had been freed of the root, during the cyclical load, all excessively had been submitted to a compression load, in a universal machine of assays (Kratos - Ltda. Dinamômetros. São Paulo - SP), regulated in the speed of 0,5 $\mathrm{mm} / \mathrm{min}$, with the force applied in the lingual face of the crown, in an angle of $45^{\circ}$ in relation to the long dental axle, until the occurrence of the any root fracture. The joined values of resistance had been following, orderly the decreasing one: $47,677 \mathrm{kgf}$ for group NMF, $34.921 \mathrm{kgf}$ for the PFM, 31,354 kgf for the PFFV and, 27,172 kgf for the ANATO. The analysis of variance applied to the original values pointed difference between the studied groups and a subsequent Tukey test $(p<0,05)$ it allowed to verify similarities between all they, with significant difference only between groups NMF and ANATO.

Keywords: Tooth Root, Tooth Endodontically-Treated, Dental Pins, Fatigue, Compressive Strength, Tooth Fractures. 
Apêndice 
Apêndice

1 - Aprovação do Comitê de Ética em Pesquisa. 
2 - Declaração de doação dos dentes. 